\title{
Changes in the variability and periodicity of precipitation in Scotland
}

Article

Accepted Version

Afzal, M., Gagnon, A. S. and Mansell, M. G. (2015) Changes in the variability and periodicity of precipitation in Scotland. Theoretical and Applied Climatology, 119 (1). pp. 135-159. ISSN 1434-4483 doi: https://doi.org/10.1007/s00704-0141094-2 Available at https://centaur.reading.ac.uk/66298/

It is advisable to refer to the publisher's version if you intend to cite from the work. See Guidance on citing.

To link to this article DOI: http://dx.doi.org/10.1007/s00704-014-1094-2

Publisher: Springer

All outputs in CentAUR are protected by Intellectual Property Rights law, including copyright law. Copyright and IPR is retained by the creators or other copyright holders. Terms and conditions for use of this material are defined in the End User Agreement.

\section{www.reading.ac.uk/centaur}

\section{CentAUR}

Central Archive at the University of Reading

Reading's research outputs online 


\title{
Changes in the variability and periodicity of precipitation in Scotland
}

Muhammad Afzal $^{\mathrm{a}}$, Alexandre S. Gagnon, ${ }^{\mathrm{b}, *}$, and Martin G. Mansell ${ }^{\mathrm{a}}$

${ }^{a}$ School of Engineering, University of the West of Scotland, Paisley PA1 2BE, Scotland, UK

${ }^{b}$ Centre For Environmental Research, School of Science, University of the West of Scotland, Paisley PA1 2BE, Scotland, UK

\begin{abstract}
This paper analyses the temporal and spatial changes in the amount and variability of rainfall in Scotland. The sequential Mann-Kendall test reveals that total annual precipitation has increased across Scotland since the 1970s with increasing trends in variability beginning between the mid1960s and the mid-1970s. Whilst temporally consistent increasing trends in precipitation totals prevail in the West, many weather stations in the East have experienced subsequent trend turning points in the following two decades, explaining the larger magnitude of the trends in western Scotland in recent decades. Trend analyses on six measures of rainfall variability indicate an increase in rainfall variability during the period 1961-2000, as measured by the intra-annual variance, the winter to summer precipitation ratio, and the annual CUSUM range, with decreasing trends observed in the number of dry days. Periodicities associated with the North Atlantic Oscillation and the Atlantic Multidecadal Oscillation could explain the observed temporal variability of rainfall.
\end{abstract}

Key words: Climate variability; periodicity; rainfall; Scotland; sequential Mann-Kendall test; trends; temporal variability; turning points; wavelet analysis

*Corresponding author: tel: +44 (0) 141848 3270; fax: +44 (0) 141848 3289. E-mail:

Alexandre.Gagnon@uws.ac.uk 


\section{Introduction}

Before the turn of the century, Arnell (1999) projected increasing trends in precipitation and runoff for Northern Europe and decreasing trends for Southern Europe under climate change and then discussed the potential implications of such projections for the managements of water resources. An examination of the precipitation records of Scotland by Smith (1995) provided further support to those projections by reporting that the increased rainfall of the 1980s and early 1990s was the largest sustained anomaly in the long term precipitation record. Werrity (2002) further identified an East-West asymmetry, adding that the above was the wettest period on record for western Scotland but not for the East. An accentuation of this East-West precipitation gradient was observed over time across the United Kingdom with the Northwest becoming wetter, notably in the winter, and the Southeast drier, especially in the summer (Mayes 2000). Such precipitation trends have continued until more recently, as reported by Macdonald et al. (2008), along with a trend towards greater flood risk in Western Scotland (Black and Burns 2002).

In addition to these trends in the magnitude of rainfall, there is evidence of an increase in rainfall variability at different time-scales (Mansell 1997). Climate change and the associated changes in the variability of rainfall are important to water resource managers (Beecham and Chowdhury 2010) as climate variability influences the planning of water infrastructure (Mason 2010). This variability can be observed in terms of gradual or step changes, or a combination of the two (Kampata et al. 2008), as well as random fluctuations, or variance, of daily, monthly, seasonal, annual, or decadal rainfall.

A number of techniques have been used to measure rainfall variability with a common measure being the variance, e.g. Mitosek (1995). However, the variance parameter does not contain any information about the sequence or pattern of such variations. The winter to summer $(\mathrm{w} / \mathrm{s})$ ratio of precipitation, defined as the ratio of winter (December-February) and summer (JuneAugust) precipitation totals can therefore be considered more useful especially with respect to water resources. This technique has previously been used by Tošić (2004) in Serbia and Montenegro, and Burt et al. (1998) and Burt and Horton (2007) in England, among others. Burt et al. (1998) noted an increase in the w/s ratio from 1881 to 1995 in North-central England, whereas Burt and Horton (2007) found no simple pattern for the period 1850-2004 at Durham in Northeast England, although since the 1960s an increase in the w/s ratio was clearly evident. 
Dry period characteristics such as the annual number of dry days, the average length of a dry period, and the maximum dry period length have also been used as measures of variability, for example, by Nasri and Modarres (2009), Serra et al. (2006), Gong et al. (2004), and Schmidli and Frei (2005) in Iran, Spain, China, and Switzerland, respectively.

The Cumulative Sum (CUSUM) of the deviations from the mean value of a reference period is a useful measure of the temporal distribution of rainfall. When calculating the CUSUM using daily precipitation data with the annual average as the reference value, a large amplitude or range in the annual CUSUM, i.e., the difference between the maximum and minimum values for each year, indicates that rainfall is concentrated over a short period in the year, while a small amplitude indicates that rainfall is more uniformly distributed throughout the year. When using a longer term average as a reference value such as the average of the entire data record, the CUSUM can be used to identify changes in trends in a time series, as a change in the direction of the CUSUM may indicate a sudden shift in the trend (Kampata et al. 2008; Smadi and Zghoul 2006).

The variability of rainfall may also be evident in terms of regular repeating patterns of varying periodicities ranging from months to decades. Identifying such periodicities, which could obviously lead to a degree of predictability in weather, has been the subject of much debate for several centuries. For example, a 35-year weather cycle was proposed back in the $17^{\text {th }}$ century (Burroughs 2003). In 1843 Heinrich Schwabe suggested that the sun's output varied in a regular way related to the number of sunspots, and it is now established that there is an 11-year sunspot cycle (Waple 1999). The influence of this 11-year sunspot cycle on rainfall has been reported in a number of studies, notably by Seleshi et al. (1994) in Addis Abada, Thomas (1993) in Rome, and Ma et al. (2010) in the Huashan mountains of China. Nevertheless, it has also been suggested by Karagiannidis (2008) that the sunspot cycle does not have an influence on precipitation in Europe, as none of the precipitation time series examined in the paper, including two weather stations in Scotland, showed periodicities related to the sunspot cycle. Likewise, Burroughs (2003) suggested that the influence of sunspot variations on rainfall is not strong .

Periodic variations in atmospheric pressure have also been shown to have significant effects on weather patterns. The El Niño Southern Oscillation phenomenon (ENSO) is perhaps the most well known and dominant mode of climate variability on Earth. It is an oscillation in atmospheric pressure in the Pacific Ocean linked to the El Niño Pacific temperature reversal event 
and is recognised to influence the European climate, possibly through variations in the position of the Northern Hemisphere jet stream (Brönnimann et al. 2006).

In Europe, the most dominant mode of inter-annual climate variability is the North Atlantic Oscillation (NAO) (Hurrell et al. 2003). The NAO refers to the difference in atmospheric pressure at sea level between the Icelandic low and the Azores high (Hurrell 1995). Positive values of the NAO coincide with a predominance of westerly winds and storm tracks passing over northern Europe, including Britain (Werritty and Foster 1998). Consequently, links between the NAO and hydro-climatic variables have been observed in northern Europe, notably by Massei et al. (2010) in France, who associated the 5-8-year and 17-year periodicities in rainfall over the Seine watershed and its river flow regime to the NAO. From 1970 onward, Massei et al. (2010) reported that positive episodes of the NAO have become more frequent and of greater amplitude; in fact, a LOESS smoothing (i.e., locally weighted polynomial fitting) of the annual NAO index indicated a shift from a negative to a positive index during the 1970 s.

A strong periodicity in average sea surface temperatures (SST) in the Atlantic Ocean has also been found and is referred to as the Atlantic Multidecadal Oscillation (AMO). In particular, a strong 65-year cycle in the AMO is evident from 1856 to the present day with a rising trend between 1910 and 1950 and again since the 1970s (Bice et al. 2012). The AMO has been correlated with regional changes in temperature and precipitation in Europe, including the United Kingdom (Sutton and Hodson 2005).

Strong periodicities of around two years have also been found in many rainfall records and have been attributed to the quasi-biennial reversal of stratospheric winds. For example, the rainfall record from Kew, England, which extends back to 1627, shows evidence of variations with periods of 2.1 and 2.4 years (Tabony 1979).

Water resource systems are developed on the basis of a stationary climate (Kizza et al. 2009). Rainfall variability and trends in rainfall totals are therefore a major concern for water companies and policy makers (Gleick and Adams 2000; Mason 2010). However, limited research has been carried out to date in Scotland on changes in the variability of rainfall. Therefore, this papers aims to identify temporal changes in the amount and variability of rainfall across Scotland using various measures of variability and to determine whether there are any spatially coherent regions showing similar trends in the amount and variability of rainfall. The periodicity of rainfall 
and the influence of different climatic oscillations and solar intensity on the temporal variability of rainfall are also examined.

\section{Data and methods}

\subsection{Sources of data}

Daily precipitation data for 40 weather stations were obtained from the MIDAS Land Surface Observations Stations Data of the UK Meteorological Office and distributed through the British Atmospheric Data Centre (BADC) (UK Meteorological Office 2006). The weather stations were selected based on the length of their data records, the percentage of missing values, and their spatial distribution. Nonetheless, the network of precipitation gauges is highest in the more populated areas of the country and comparatively sparse in some areas such as the north-western highlands (Sweeney and O'Hare 1992). A description of the selected weather stations and their temporal coverage is given in Table 1 while Figure 1 illustrates their geographical distribution. All selected time series have at least 30 years of data with no more than $5 \%$ missing values per year. To identify whether there are spatially coherent regions showing similar trends in rainfall amount and variability, a subset of 22 weather stations was selected with a common rainfall record 19612000. The grey circles in Figure 1 represent these 22 weather stations.

The annual and winter station-based NAO index for the period 1880-2010 were downloaded from the Climate Analysis Section of the National Center for Atmospheric Research (http://www.cgd.ucar.edu/cas/jhurrell/indices.html). The downloaded annual NAO time series corresponds to the normalised sea level pressure (SLP) difference between Ponta Delgada in the Azores and Stykkisholmur/Reykjavik in Iceland while the winter (December-February) index of the NAO uses the sea level pressure of Lisbon, Portugal, instead of the Azores. Since 2003 the NCEP/NCAR Reanalysis grid point closest to Ponta Delgada was used as a substitute because of the discontinuation of pressure measurements at that weather station. The SLP anomalies at the two weather stations were normalised using the $1865-1984$ base period.

The monthly values of the AMO index since 1856, from which an annual average was calculated, was provided by the Earth System Research Laboratory of the National Oceanic and Atmospheric Administration (http://www.esrl.noaa.gov/psd/data/correlation/amon.us.long.data) (Enfield et al. 2001). The AMO is an index of SST in the North Atlantic and is calculated using an area-weighted average of SST between the equator and $70^{\circ} \mathrm{N}$ with the SST measurements 
originating from version 2 of the Kaplan dataset. The unsmoothed and de-trended version of the dataset was used in the present study.

The annual sunspot index data were obtained from Solar Influences Data Analysis Centre (SIDC; http://sidc.oma.be/sunspot-data) for the period 1910-2008 (SIDC-team, World Data Center for the Sunspot Index, Royal Observatory of Belgium).

\subsection{Trend analyses}

The magnitude of the trends was determined using the Theil Sen Approach (TSA). This technique estimates the trend slope from the median of slopes between all pairs of data points and is therefore more robust to the influence of outliers (Sen 1968). The statistical significance of the trends was assessed using the associated Mann Kendall (MK) test on a consistent time-period of analysis extending over the period 1961-2000. For this purpose, the 'zyp' package of the R Project for Statistical Computing (http://www.r-project.org/) was used (Hamed 2008). The MK test is a non-parametric technique; it is robust to the influence of extremes and is thereby more appropriate for skewed data (Gagnon and Gough 2005; Beecham and Chowdhury 2010). Explanations of the MK statistical test and its application in climatology and water resources are widely documented in the literature (e.g. Beecham and Chowdhury (2010); Burn and Elnur (2002); Helsel and Hirsch (2002), Kapouzos et al. (2010)).

If observations in a time series are correlated with the preceding or succeeding observations then serial correlation exists in that time series. The MK test, however, is only valid if there is no serial correlation in a time series because positive serial correlation increases the variance of the dataset and hence the likelihood of the MK statistical test to erroneously detect a statistically significant trend (Gagnon and Gough 2005; Partal and Kahya 2006). Therefore, a correction for serial correlation following the procedure by Yue et al. (2002) was made prior to using the MK test. The procedure consisted of first removing the trend from the time series when it differed from zero; in that case it was assumed to be linear and the trend was estimated using the

TSA. Second, the lag-1 autocorrelation coefficient of the de-trended time series was computed and when it was found to be statistically significant at the $95 \%$ confidence level the autoregressive component, i.e., AR(1), was removed from the de-trended time series. Third, the trend and the residuals of the autoregressive process were added together and the MK test was applied to the resulting time series. 
The sequential version of the MK test is widely used to determine the approximate beginning and/or changes in trend in a time series (Bednorz and Kossowski 2004; Gerstengarbe and Werner 1999; Modarres and Sarhadi 2009; Partal and Kahya 2006). In this test individual values in a time series $\left(\mathrm{x}_{\mathrm{j}}\right)$ are compared with all preceding values and the number $\left(\mathrm{n}_{\mathrm{j}}\right)$ of preceding values less than $x_{j}$ recorded. The test statistic $t_{j}$ is the sum of $n_{j}$, i.e.:

$$
t_{j}=\sum_{1}^{j} n_{j}
$$

To see the change in trend with time, the sequential values $u(t)$ are calculated where

$$
u(t)=\frac{t_{j}-E(t)}{\sqrt{\operatorname{var}\left(t_{j}\right)}}
$$

and $E(t)$ and $\operatorname{var}(t)$ are the mean and variance of the test statistic, respectively, and are given below:

$$
\begin{gathered}
E(t)=\frac{j(j-1)}{4} \\
\operatorname{var}\left(t_{j}\right)=\left[\frac{j(j-1)(2 j+5)}{72}\right.
\end{gathered}
$$

Similarly, the values of $u^{\prime}(t)$ are computed backwards, starting from the end of the time series (Modarres and Sarhadi 2009). The intersection of the forward, $u(t)$, and backward, $u$ '( $(t)$, lines and their subsequent divergence from each other can be considered as the beginning of a trend or a change point in the temporal behaviour of a time series (Partal and Kahya 2006), which in this paper will be referred to as a change in trend or a trend turning point. The latter refers to the point at which the trend changes from an upward to a downward direction or vice versa (Węglarczyk 2009; Yang and Tian 2009). As in Nasri and Modarres (2009), in a few cases, a change point was identified even though the forward and backward lines did not cross each other, but came close to each other before diverging. These exceptions are mentioned in the results section and were included because a clear change point was identified through visual inspection of the original time series. Figure 2 illustrates how the sequential MK test identifies the beginning of a trend and subsequent trend turning points in different total annual precipitation time series. 


\subsection{Change in mean (step change)}

It has been noted that in some cases there might a step change in the mean value of the time series rather than a linear (i.e., gradual) trend. The location and significance of such a step change can be estimated using the Worsley Likelihood Ratio (WLR) test (Worsley 1979). This test determines whether the means of two parts of a time series are significantly different and if so estimates the most likely time of the change. If a time series is split at $k$ with the mean of $x_{1}, \ldots, x_{k}$ $=\mu_{k}$ and the mean of $x_{k+1}, \ldots, x_{n}=\mu^{\prime}{ }_{k}$, then the within-groups sum of the squares of the deviations is calculated as:

$$
S_{k}=\sum_{i=1}^{k}\left(x_{i}-\mu\right)
$$

for $k=1,2, \ldots, n$; where $n$ is the length of the time series and $S_{0}=0$. The normalised betweengroup sum of the squares is given by:

$$
T_{k}^{2}=\left[k \frac{n-k}{n}\right]\left(\mu_{k}-\mu_{k}^{\prime}\right)^{2}
$$

for $k=1,2, \ldots, n-1$. The likelihood ratio test is based on the statistic:

$$
W=\left[\left(\max (n-2)^{1 / 2}\right)\left|T_{k}\right| / S_{k}\right]
$$

and the level of significance for the values of $W$ was determined using Worsley (1979).

\subsection{Best characterisation of the precipitation record}

In the case that both the outcomes of the sequential MK test and the WLR test are positive at any weather station, for example, if the sequential MK test indicates a change in trend on a specific year in a time series while the WLR test indicates that a step change exists at around the same time in the same time series, an additional analysis was done so as to determine what best characterises the precipitation record. A precipitation time series could be categorised as experiencing (1) a gradual trend over the consistent time period of analysis (i.e., the outcome of the MK test), (2) a trend beginning on a specific year or with a trend turning point during the study period (i.e., the outcome of the sequential MK test), or (3) a step change in the time series (i.e., the outcome of the WLR test). The analysis consisted of calculating the variance of the residuals by modelling the time series using the three above options with the option with the smallest ratio of the variance of the residuals to the variance of the original precipitation time series being the best characterisation of the precipitation record. For example, in the first option above (i.e., gradual 
trend), the analysis consisted of calculating the variance of the residuals from the trend line; in the second case the residuals were calculated from the trend lines before and after the change in trend; while in the third case the residuals were calculated from the mean of the time series before and after the step change.

\subsection{Measures of variability}

The variability of rainfall was measured using the intra-annual variance, i.e., the variance of the monthly precipitation totals for each year; the w/s precipitation ratio; the annual CUSUM range; the number of dry days per year with a dry day defined as a day with less than $0.2 \mathrm{~mm}$ of precipitation, a threshold commonly used in the literature (e.g. Fowler and Kilsby (2002)); the average dry spell length, and the maximum length of a dry period. The w/s ratio was defined as the ratio of average winter precipitation (December-February) to the average summer (June-August) precipitation. The average precipitation ratio was used as opposed to the ratio of total seasonal precipitation as a way to minimise the effect of missing values in the data, which were nonetheless limited. The annual CUSUM range was calculated by subtracting the maximum CUSUM value from the minimum CUSUM value for each year where the CUSUM refers to the cumulative sum of differences between the values of a time series and the average of the series, i.e.:

$$
S_{i}=S_{i-1}+\left(\mathrm{X}_{i}-\overline{\mathrm{X}}\right)
$$

for $i=1,2, \ldots, 365$. The cumulative sum begins with $\mathrm{S}_{0}=0$ and since the average is subtracted from each value, the cumulative sum also ends at zero $\left(S_{365}=0\right)$.

Ideally there should be some degree of consistency between the various measures of variability. The Pearson's correlation coefficient was calculated between each of the six measures of variability (Table 2). Correlation coefficients above 0.304 were considered statistically significant at the 95\% confidence level (Murdoch and Barnes 1974).

\subsection{Periodicity}

The periodicity of the total annual precipitation time series was measured using autocorrelation and wavelet analysis. Where the trend differed from zero, the data were de-trended before performing the autocorrelation analysis. Wavelet analysis is a spectral analysis technique that identifies periodicities in both the time and frequency domains (Beecham and Chowdhury 2010). For this purpose, a modified version of the 'dplR' package of the R Project for Statistical 
Computing was used with the continuous wavelet transform plot obtained using the Morlet approach (Torrence and Compo 1998), as this approach and has been found to be appropriate for hydrological analyses (Beecham and Chowdhury 2010).

\section{Results}

\subsection{Trends in total annual precipitation}

Several authors have noted a divergence in precipitation trends between western and eastern Scotland, especially since the 1960s (Barnett et al. 2006; Macdonald et al. 2008; Smith 1995; Werrity 2002). For this reason, the results of the trend analyses, although presented at individual weather stations, are divided into the three Scottish regions commonly referred to in the literature, i.e., North, West, and East Scotland (Figure 1). Such a division clearly shows the EastWest precipitation asymmetry over Scotland with a mean total annual precipitation of approximately $1494 \mathrm{~mm}$ in the West and $802 \mathrm{~mm}$ in the East (Table 1), which is the result of the prevailing weather systems travelling eastward across the country and the effect of orography on precipitation.

The computations of the TSA and MK test calculated over the period 1961-2000 indicate an increase in total annual precipitation at all but one weather station with statistically significant trends detected at 14 of the 22 stations (Figure 3 ). The analyses also show that the precipitation trends are more pronounced in the West of Scotland than in the East with the average of all weather stations in the West showing an increase of $0.71 \mathrm{~mm}$ per year in comparison to $0.30 \mathrm{~mm}$ per year in the East. North Scotland only has one weather station with data available throughout the consistent time-period of analysis, which shows a trend towards increasing precipitation of similar magnitude to the average of the East region stations.

The results of the sequential MK test indicate a concentration of change points in the total annual precipitation time series in the 1970s (Figure 4). Although many weather stations have data records during the 1960s, at only two weather stations was the beginning of a trend detected during that decade. Prior to the 1960 s, the number of weather stations with data is limited. One weather station in the West of Scotland (i.e., Paisley) and another station in the North (i.e., Cluny Castle) show the beginning of a decreasing precipitation trend in the early 1940s. The beginning of an increasing trend in precipitation is seen in the 1930s at two weather stations in north-eastern 
Scotland, but no other weather station has experienced any change point towards increasing precipitation until the 1970s.

The total annual precipitation time series were grouped into four categories based on the outputs of the sequential MK test since 1970: a unidirectional trend (i.e., no change in trend), a single change in trend, two trend turning points, and multiple changes in trend. Figure 2 provides an example for each of those four categories. At Blackwood, for instance, the forward and backward lines of the sequential version of the MK test do not cross each other throughout the length of the data record and accordingly no change in trend is recorded at that weather station (Figure 2a). This pattern is seen at five weather stations plus one additional weather station in North Scotland, i.e., Greenland, which does not have a complete data record throughout the 1970s. In the second category, the sequential lines of the MK test cross each other and diverge in the midto-late 1970 s, indicating the beginning of an increasing trend in total annual precipitation at that time (Figure 2b). At Skipness, the beginning of an increasing trend in precipitation is also detected in the 1970s, but it reverses in the 1980s (Figure 2c); while at Edinburgh the decreasing trend that also began in the early 1980s further reverses towards increasing precipitation in the 1990s (Figure $2 \mathrm{~d})$.

The second pattern, as represented by Gailes in Figure 2, is seen at 26 of the 37 weather stations with data throughout the 1970s. At these 27 weather stations, a clear change in trend towards increasing precipitation is seen during the 1970s (Figure 4). In addition, Craggie, whose data record began in 1973, shows the beginning of an increasing trend in precipitation in the late 1970s, which is in agreement with the above pattern of a trend towards greater precipitation starting in the 1970 s and could therefore be included with the above 26 stations. Two additional weather stations, i.ie., Islay and Mull in the Inner Hebrides, did not show any change point prior to the early-to-mid 1980s. However, at these stations, a visual inspection of the precipitation time series could arguably identify the beginning of an increasing trend in total annual precipitation in the late 1970s since the forward and backward lines of the sequential version of the MK test first crossed each other around 1976-77, and then overlapped and crossed each other a number of times prior to diverge in the early 1980s; such an interpretation of this technique was used in other studies (e.g. Lazaro et al. (2001) and Partal and Kahya (2006)).

At 15 of the weather stations showing an increasing trend in precipitation in the 1970 s, there was either no further change in trend or in the case of six stations a change in the magnitude 
of the increase is seen (c.f. Figure 4). Spatially, the 15 weather stations falling in this category are more prevalent in the West and in the highlands of northern Scotland. Twelve stations, including many weather stations in the East and all of those bordering the Firth of Forth, had a trend reversal, i.e., a subsequent trend turning point towards decreasing precipitation in the late 1970s or early 1980s as illustrated by Skipness in Figure 2c. Six of these weather stations, with the example of Edinburgh provided in Figure 2d, experienced a third trend turning point towards increasing precipitation in the 1990s. These six weather stations with multiple changes in trend are all situated in eastern Scotland.

\subsection{Step changes in total annual precipitation}

The results of the WLR test, when run over the period 1961-2000, reveal a statistically significant step change in the total annual precipitation time series in the 1970s at nine weather stations plus in the early 1980s at one additional station with a clustering in the West of Scotland (Figure 5). A further four weather stations also show a step change at the same time albeit not statistically significant. A representative example is shown in Figure 6a, which clearly illustrates a step change in 1978 in the total annual precipitation time series of Blackwood.

At a number of those weather stations where the WLR identified a step change, the sequential MK test had indicated the beginning of a trend or a trend turning point at around the same time. Figure $6 \mathrm{~b}$ depicts the example of Garpel Burn where the sequential MK revealed an increasing trend in precipitation beginning in 1977 while the WLR indicates that a step change occurred in 1978 . Hence the question is what would be considered as the best characterisation of the precipitation record at those weather stations in the West of Scotland: a step change with no trend before and after or a change point towards increasing precipitation as identified by the sequential MK test? Calculating the ratio of the variance of the residuals to the variance of the original time series reveals that at three weather stations, i.e., Leadhills, Glassford, and Blackwood, a step change was found to best characterise the precipitation records while the results of the sequential MK test are to be favoured in all other cases.

\subsection{Rainfall variability - average and trends}

Similar to mean total annual precipitation, an East-West asymmetry is also observed in a number of measures of rainfall variability. The intra-annual variance of precipitation and the annual CUSUM range, which both represent the distribution of rainfall within a year, are higher in 
the West than in the East, although not as a proportion of annual precipitation so that the coefficient of variation did show a great difference between East and West (Table 1). The w/s ratio of precipitation indicates that in the West the winter records 1.7 more total precipitation than the summer and this ratio decreases to 1.2 in the East. On average, there are approximately 156 dry days per year in the East and 139 in the West, however, there is no significant East-West differences in the average length of a dry period or the maximum length of a dry period in a year. Accordingly, the depiction of the annual CUSUM range at individual weather stations clearly shows higher rainfall variability in the West of Scotland than in the East and North of the country when averaged over the period 1961-2000 (Figure 1). A similar East-West pattern is seen in the intra-annual variance, the w/s precipitation ratio, and the annual number of dry days per year (not shown), which is not surprising given that the correlation between these four measures of rainfall variability was found to be statistically significant (c.f. Table 2).

The trends in the variability of rainfall during the period 1961-2000 reveal that the intraannual variance of precipitation has increased over time at all but one weather station, and that the trends are statistically significant at the majority of the weather stations situated in the West of the country (Figure 7). Most of the trends in the w/s precipitation ratio are statistically significant and show a tendency for winters to become wetter and/or summers drier. The direction of the trends in the annual CUSUM range is similar to that of the intra-annual variance with most weather stations in the West showing statistically significant increasing trends. The annual number of dry days was found to be decreasing significantly at 13 of the 22 weather stations, which is in agreement with increasing trends in total annual precipitation. Very few trends in the average dry spell length and the maximum dry spell length are statistically significant and those that are show increasing trends. This reveals an interesting pattern at some weather stations; for example, Loch Calder in North Scotland shows an increase in the average and maximum length of a dry period in a year even though the annual number of dry days is decreasing.

The application of the sequential MK test on the six measures of rainfall variability reveals that 30 weather stations experienced the beginning of an increasing trend in the intraannual variance of precipitation between the mid-1960s and the mid-1970s (Figure 8a). An additional three weather stations also show the beginning of an increasing trend in the first half of the 1960s, leaving five weather stations with data available throughout the 1960s and 1970s without a change in trend towards increasing variance during that period. Nonetheless, these five 
weather stations experienced a continuous increase in precipitation variance since their data record began. Therefore, at all weather stations was the intra-annual precipitation variance increasing throughout the 1960 s and 1970 s or began to increase during that period.

In addition, as for the total annual precipitation analyses, at some weather stations the increasing trends in intra-annual variance that began in the 1960 s or 1970 s subsequently reversed in the early-to-mid 1980s. In fact, 14 weather stations across Scotland experienced a change point towards decreasing variance in the 1980s (Figure 8a). At other weather stations, the increasing trend beginning in the 1960s or 1970s stopped in the early-to-mid 1980s after which there was no overall trend, i.e., the forward and backward lines of the sequential version of the MK test overlapped several times (Brunetti et al. 2001) This trend reversal in the 1980s or the lack of an overall trend after that time might provide an explanation for the lack of statistically significant trends at some weather stations over the consistent time period of analysis, particularly, in the North and East of the country (c.f. Figure 7).

There is a clustering of weather stations with the beginning of an increasing trend in the w/s precipitation ratio around the mid-1960s with a few additional weather stations experiencing this change in the early 1970s (Figure 8b). These increasing trends persisted until the end of the data records at 14 weather stations, while they subsequently reversed in the late 1980s or around the mid-1990s at eight weather stations. At ten weather stations no change in trend was observed since the 1960s and the w/s precipitation ratio increased continuously throughout the length of the data record, resulting in 24 weather stations having experienced a trend towards wetter winters and/or drier summers without subsequent reversal in recent decades.

The annual CUSUM range results display a similar pattern to that of the intra-annual variance of precipitation in that there is a clustering of change points towards increasing values between the mid-1960s and the mid-1970s (Figure 8c). Thirty weather stations showed a positive change in trend between the mid-1960s and the mid-1970s. For 15 of the stations the trend continued uninterrupted until the end of the data record and at a further three weather stations a continuous increase was observed since at least the 1960s (i.e., increasing trend without any change point). In a way similar to the other two measures of variability previously described, a trend turning point towards decreasing values was also observed in the early 1980s, this was found at 10 weather stations; and in the late 1970 s at an additional five other stations. 
No clear pattern could be identified from the application of the sequential MK test on the dry period analysis, i.e., the number of dry days per year, the average length of a dry period, and the maximum dry spell length (Figure 8d,e,f). A number of change points towards an increase in the average and maximum length of a dry period is seen at a number of weather stations in the mid-1960s, but the trends are not temporally consistent, which explain why few of the trends seen in Figure 7 are statistically significant as well as the weak magnitude of those trends.

\subsection{Periodicity of rainfall}

The auto-correlation analysis on the total annual precipitation time series showed several weather stations with statistically significant auto-correlations at the $95 \%$ confidence level at a lag of 2 and 4 years as well as at lag of 7-8 years, particularly in the West (Figure 9). Some of these periodicities can also be seen in the wavelet analyses. The wavelet analyses identified prominent cycles at 2-4, 4-7, 7-10 and 16-24 years across Scotland. Table 3 displays the time-period during which these four ranges of periodicities were identified at individual weather stations. The upper two quartiles of the wavelet transform energy were considered when constructing Table 3; this threshold is arbitrary and was set to identify the maximum number of periodicities. As an example, Figure 10 illustrates that at Balmoral, periodicities of 2-4, 7-10, and 16-24 years were present. The 16-24-year periodicity at Balmoral was continuous from the 1960s onwards while the influence of the 7-10-year periodicity was strong throughout the 1960s and 1970s, weakened during the 1980s, and strengthened again in the 1990s (Figure 10).

Table 3 indicates that periodicities of 16-24-year are widespread across Scotland although outside the cone of influence at many weather stations due to the length of some data records. The 7-10-year periodicities are common throughout the data records of many weather stations in the North and East but are more dominant after around 1980 in the West. Periodicities of 4-7-years are limited in their temporal and spatial extent compared to the other periodicities. The 2-4-year periodicities are common across the country albeit highly localised in time. Other longer periodicities centred on 32 years and 64 years are seen at some weather stations, notably at Balmoral for the 32-year periodicity (c.f. Figure 10), but are outside the cone of influence at other weather stations. 


\section{Discussion and conclusion}

The results of the trend analyses indicate that total annual precipitation has increased during the period 1961-2000 across Scotland with the sequential MK test revealing that these increasing trends began in the 1970s. At half of those weather stations, however, there was a subsequent trend turning point towards decreasing precipitation in the late 1970s/early 1980s, which further reversed towards increasing precipitation in the 1990s at six weather stations in the East. In addition, it was found that the increasing trends in precipitation during the period 19612001 at three weather stations in the West of Scotland were the result of a step change in the 1970s with no trend before and after that change point.

Statistically significant increasing trends in rainfall variability were also detected at the majority of the weather stations, particularly in the West of the country. In terms of percentage change, the trends in rainfall variability are of greater magnitude than those of total annual precipitation. The majority of weather stations experienced an increase in intra-annual variance and the annual CUSUM range beginning between the mid-1960s and the mid-1970s. These increasing trends in variance either: (1) continued until the end of the data records; (2) reversed to decreasing trends in the 1980s; or (3) lasted until the mid-1980s after which no trend was observed. The dominant pattern for the annual CUSUM range time series was similar with 15 weather stations showing increasing trends since the 1960s until the end of the data records but a reversal of the increasing trends was seen in the late 1970s/early 1980s at 15 other weather stations.

Trend analyses on the w/s ratio of precipitation reveal that winters have become wetter and/or summer driers at the majority of the weather stations with many increasing trends beginning in the mid-1960s or early 1970s. Some w/s precipitation ratio time series experienced a trend reversal in the late 1980 s or mid-1990s, which could explain the lack of statistically significant increasing trends at those weather stations during the period 1961-2000. The number of dry days per year was found to be decreasing at the majority of the weather stations across Scotland. No clear temporal or spatial patterns were observed in the time series related to the average and maximum length of a dry period, although a tendency for longer dry periods was observed, albeit of weak magnitude and with very few weather stations showing statistical significance. 
These results indicate that Scotland has become wetter since the 1970s and that the variability of precipitation within years has increased although possibly not as a proportion of total annual precipitation. The tendency for precipitation to be concentrated in one part of the year has increased, as indicated by the positive trends in the intra-annual precipitation variance and the annual CUSUM range, and the increase in the w/s precipitation indicates that winters are becoming wetter and/or summers drier. Analysis on the dry period characteristics indicate that the number of dry days per year has decreased but with a tendency for dry periods to be longer, although not significantly at many weather stations.

These results agree with those of Barnett et al. (2006) who examined trends in precipitation totals across Scotland. They found that Scotland has become wetter at the annual time-scale with statistically significant trends found in the winter season only. Regionally the trends were of largest magnitude in the western and northern regions of the country, as found in the current study. In the summer, a small increase in rainfall was found in the West and a decrease in the North, although all the summer season trends lacked statistical significance. The sequential MK was not applied to determine the potential beginning year of the precipitation trends.

Mansell (1997) also found an increase in the intra-annual variance of precipitation at Paisley since about 1970. Previous research analysing the variability of rainfall in the UK, however, has to date focused on the analysis of the w/s precipitation ratio. Jones and Conway (1997) found a 30\% increase in precipitation in Scotland for the season November to April when comparing the period 1986-2005 with that of 1951-1980. Conversely, the change between these two time periods for the other six months of the year was marginal. Mansell (1997) noted that most of the increase in total annual precipitation observed during the period 1885-1994 at Paisley was due to an increase in winter precipitation. Similar changes in the w/s ratio have been observed in England and Wales where an increase is seen when comparing the 1961-1990 period to the 1941-1970 period (Mayes 1996). At Durham (northeast England) Burt and Horton (2007) observed that during the $20^{\text {th }}$ century winters had become wetter and summers drier, and that this increase in the w/s ratio was particularly evident since the 1960s. Osborn et al. (2000) further added that there is evidence of an increase in the intensity of daily precipitation amounts in winter and a decrease in the summer in the UK during the period 1961-1995. These increasing trends in the w/s ratio agree with the results of the present study. 
The most prevalent periodic cycles in total annual precipitation were 2-4, 4-7, 7-10 and 16-24 years with longer periodicities centred on 32 years and 64 years seen in the longer time series. Mansell (1997) also observed a 18-year periodicity in the Paisley precipitation data using Fourier analysis. The 7-10-year periodicities may be attributed to the NAO, which has shown an 812 year periodicity since the mid 1970s (Figure 11). This agrees with the results of Butler et al. (1998) who found a prominent spectral peak in both the annual and winter NAO indices at 7.65 years and Hurrell and van Loon (1997) who found enhanced power in the 6-10-year band in the winter NAO time series. The smaller periodicities of 2-4 years may be attributed to the quasibiennial reversal of stratospheric winds (Burroughs 2003).

It is suggested that the positive trends in precipitation in Scotland since the 1970s are related to changes in atmospheric circulation patterns associated with the NAO, which changed from a negative to a positive phase in the 1970s (Massei et al. 2010), and whose power spectra is enhanced beginning in that decade (c.f. Figure 11). This enhancement of the power spectra in the annual NAO time series in the 1970s is also seen in the winter NAO time series (not shown), which is known to dominate the winter climate of northern Europe. Similarly, Fealy and Sweeney (2005) calculated the CUSUM of the winter NAO and found the existence of a change point in the 1970s, which they associated with more positive values of the NAO. In general, a higher NAO index leads to stronger westerly winds across the British Isles, resulting in increased moisture transport and precipitation over Scotland. Since the impact of the NAO in Europe is strongest in the winter, this might explain the change point in rainfall variability around 1970 at many weather stations, notably for the w/s ratio, and the associated decrease in the number of dry days per year, particularly in the West. Accordingly, Hannaford and Marsh (2006) found strong positive correlation coefficients between winter runoff and the winter NAO in Scotland, particularly for catchments exposed to westerly airflows.

Rainfall records are very noisy (Kundzewick and Robson 2004) and the trend turning points identified in the 1980s and 1990s at a number of weather stations in the East of Scotland could be the result of random variations in the time series rather than being the result of any physical mechanism, especially in view that these turning points result in 'trends' of relatively short duration. However, using the method described in Sneyers (1990) revealed that many of the trend turning points in the 1980 s, but only one during the 1990 s, were above the signal to noise ratio in addition to the majority of those detected during the 1970s for which a physical explanation was 
provided above. Since no East-West asymmetry was observed in the occurrence of periodicities of less than 10 years (c.f. Table 3), these short term periodicities could not provide a cause for the occurrence of the latter trend turning points in the East of the country.

Werrity and Foster (1998) used a dataset of the Lamb's weather types, which were constructed using surface synoptic charts, and thus represent the state of the atmospheric circulation for different locations across the UK. They noted that Scotland is influenced by two types of weather systems: Westerly and Cyclonic systems. They found that weather stations in the West are positively correlated with Westerly systems whereas Cyclonic systems prevail in the East. On the one hand, Westerly systems peaked in the 1920s and then declined until the 1970s after which they increased. These Westerly systems were found to be strongly correlated to the NAO and the occurrence of this increase in Westerly systems since the 1970s gives further support for the physical mechanism provided above for the change points in the 1970 s observed in the precipitation time series. On the other hand, Cyclonic systems have shown a steady rise from the 1940 until the 1980s during which they declined but then increased again in the 1990s (Werritty and Foster 1998). This temporal pattern reflects the behaviour of the precipitation time series of eastern Scotland and these changes in Cyclonic systems could explain the trend reversals in the total annual precipitation time series seen in this paper in the 1980 s and again in the 1990 s .

SSTs in the North Atlantic also influence the hydro-climatology of Europe (Arnell 1999). For example, Benestad and Melsom (2002) found an association between North Atlantic SSTs and an unusual rainfall event in Norway, Lorenzo et al. (2010) demonstrated the use of North Atlantic SSTs to predict the variability of rainfall in the North West of the Iberian Peninsula, and Phillips and McGregor (2002) identified a relationship between North Atlantic SSTs and rainfall in the South West of England. One index of SST in the North Atlantic is the AMO and Sutton and Hodson (2005) associated the positive phase of this oscillation with greater precipitation in western Europe, because a positive AMO favours cyclonic conditions over the North Atlantic and Europe (Knight et al. 2006). This 65-year oscillation is seen in the power spectra of the longest Scottish precipitation time series and its impact may also be significant in terms of the recent positive trends, since its most recent cycle also began in the 1970s (Figure 12).

The inspiration behind this study is the perception that climate variability is likely to increase the variability of the hydrological cycle in many regions, thus increasing uncertainty about the availability of water resources in the future. The determination and assessment of risks to 
water supply systems is based on probabilities based on information gathered from historical records (Lopez et al. 2011). Such an approach is justified under the assumption of a stationary climate, including the assumption that "the system fluctuates within an unchanging envelope of variability" (Milly et al. 2008, p. 573). However, anthropogenic climate change influences how our systems function beyond natural variability (Milly et al. 2008).

The results of this study indicate that in addition to the trends in precipitation totals, the variability of rainfall has been increasing through a greater spread of the rainfall values, but the temporal distribution of rainfall has also been changing, becoming less uniform through an increase in the $\mathrm{w} / \mathrm{s}$ precipitation ratio. The increasing variability of rainfall has obvious implications for water companies as it implies a reduced reliability of storage especially in the case of run-of-river supplies. The vulnerability of a given storage system under a variable rainfall input depends on the amplitude of the variation and the period of the variation. Storage systems are particularly vulnerable to long period and/or large amplitude variations. Reservoirs could be vulnerable for periodicities of 10 years or more noted in some records whereas run-of-river intakes are obviously vulnerable to shorter period variations, depending on the intake flow in relation to the mean river flow. In the West of Scotland the increased rainfall variability is mitigated by the general increase in rainfall although, as seems apparent, much of the increase is in the winter months and the increased flows into reservoirs may not result in increased storage if the reservoir is already full. In the East the increase in rainfall is less in proportion to the increase in variability and therefore one would expect the reservoir reliability to be less. It should also be remembered that, the reservoir inflow variability is affected by variations in evapotranspiration as well as rainfall. The effect of climate variability on reservoir reliability is the subject of further on-going research by the authors.

Rainfall variability may also have an effect on hydro power generation which is significant in Scotland. However, most large schemes include significant storage reservoirs and the increased winter flows will be compatible with the peak electricity demand. In addition the demand for hydro power is more flexible than the demand for water.

Further analysis is required at the seasonal time-scale especially on the dry period characteristics, and using outputs from regional climate models to determine whether the trends presented here are likely to continue into the future and eventually affect the reliability of water supply systems across the country. 


\section{Acknowledgement}

The authors are thankful to the British Atmospheric Data Centre (BADC) for providing the daily precipitation data, which were downloaded from URL: http://badc.nerc.ac.uk/mybadc. The authors also wish to thank Dr Ewan MacArthur for answering our statistical queries and Ms Irina Foss for her help with the wavelet analyses. In addition we thank all scientists who have made their $\mathrm{R}$ packages available online. A.S. Gagnon acknowledges financial support from the Scottish Alliance for Geoscience, Environment and Society (SAGES).

\section{References:}

Arnell NW (1999) The effect of climate change on hydrological regimes in Europe: a continental perspective. Global Environmental Change 9:5-23

Barnett C, Hossell J, Perry M, Procter C, Hughes G (2006) Patterns of climate change across Scotland: Technical Report. SNIFFER Project CC03. Scotland \& Northern Ireland Forum for Environmental Research, Edinburgh

Bednorz E, Kossowski T (2004) Long-term changes in snow cover depth in eastern Europe. Climate Research 27:231-236

Beecham S, Chowdhury RK (2010) Temporal characteristics and variability of point rainfall: a statistical and wavelet analysis. International Journal of Climatology 30:458-473

Benestad RE, Melsom A (2002) Is there a link between the unusually wet autumns in southeastern Norway and sea-surface temperature anomalies? Climate Research 23:67-79

Bice D, Montanari A, Vučetić V, Vučetić M (2012) The influence of regional and global climatic oscillations on Croatian climate. International Journal of Climatology 32:1537-1557

Black AR, Burns JC (2002) Re-assessing the flood risk in Scotland The Science of the Total Environment 294:169-184

Brönnimann S, Xoplaki E, Casty C, Pauling A, Luterbacher J (2006) ENSO influence on Europe during the last centuries. Climate Dynamics 28:181-197

Brunetti M, Maugeri M, Nanni T (2001) Changes on total precipitation, rainy days and extreme events in northeastern Italy. International Journal of Climatology 21:861-871

Burn DH, Hag Elnur MA (2002) Detection of hydrologic trends and variability. Journal of Hydrology 255:107-122

Burroughs WJ (2003) Weather Cycles Real or Imaginary Cambridge University Press, Cambridge

Burt TP, Adamson JK, Lane AMJ (1998) Long-term rainfall and streamflow records for north central England: putting the Environmental Change Network site at Moor House, Upper Teesdale, in context. Hydrological Sciences Journal 43:775-787

Burt TP, Horton BP (2007) Inter-decadal variability in daily rainfall at Durham (UK) since the 1850s. International Journal of Climatology 27:945-956

Butler CJ, Coughlin ADS, Fee DT (1998) Precipitation at Armagh Observatory 1838-1997. Biology and Environment: Proceedings of the Royal Irish Academy 98B:123-140

Enfield DB, Mestas-Nunez AM, Trimble PJ (2001) The Atlantic Multidecadal Oscillation and its relation to rainfall over river flows in the continental U.S. Geophysical Research Letters 28:2077-2080

Fealy R, Sweeney J (2005) Detection of a possible change point in atmospheric variability in the North Atlantic and its effect on Scandinavian glacier mass balance. International Journal of Climatology 25:1819-1833

Fowler HJ, Kilsby CG (2002) Precipitation and the North Atlantic Oscillation: a study of climatic variability in Northern England. International Journal of Climatology 22:843-866

Gagnon AS, Gough WA (2005) Trends in the dates of ice freeze-up and break-up over Hudson Bay, Canada. Arctic 58 370-382

Gerstengarbe F-W, Werner PC (1999) Estimation of the beginning and end of recurrent events within a climate regime. Climate Research 11:97-107

Gleick PH, Adams DB (2000) Water: The Potential Consequences of Climate Variability and Change for the Water Resources of the United States. Pacific Institute for Studies in Development, Environment, and Security,

Gong D-Y, Shi P-J, Wang J-A (2004) Daily precipitation changes in the semi-arid region over northern China. Journal of Arid Environments 59:771-784

Hamed KH (2008) Trend detection in hydrologic data: The Mann-Kendall trend test under the scaling hypothesis. Journal of Hydrology 349:350- 363 
Hannaford J, Marsh T (2006) An assessment of trends in UK runoff and low flows using a network of undisturbed catchments. International Journal of Climatology 26:1237-1253. doi: $10.1002 /$ joc. 1303

Helsel DR, Hirsch RM (2002) Statistical Methods in Water Resources. Techniques of WaterResources Investigations, Book 4, chapter A3.

Hurrell JW (1995) Decadal trends in the North Atlantic Oscillation and relationships to regional temperature and precipitation. Science 269:676-679

Hurrell JW, Kushnir Y, Ottersen G, Visbeck M (2003) The North Atlantic oscillation: climatic significance and environmental impact. Geophysical Monograph Series 134:1-35

Hurrell JW, van Loon H (1997) Decadal variations in climate associated with the North Atlantic Oscillation. Climatic Change 36:301-326

Jones PD, Conway D (1997) Precipitation in the British Isles: An analysis of area-average data updated to 1995. International Journal of Climatology 17:427-438

Kampata JM, Parida BP, Moalafhi DB (2008) Trend analysis of rainfall in the headstreams of the Zambezi River Basin in Zambia. Physics and Chemistry of the Earth 33:621-625

Karagiannidis AF, Bloutsos AA, Maheras P, Sachsamanoglou C (2008) Some statistical characteristics of precipitation in Europe. Theoretical and Applied Climatology 91:193204

Karpouzos DK, Kavalieratou S, Babajimopoulos C (2010) Trend analysis of precipitation data in Pieria Region (Greece). European Water 30:31-40

Sneyers R 1990 On statistical analysis of series of observations. Technical Note No 143. Geneva. Switzerland. World Meteorological Society

Kizza M, Rodhe A, Xu CY, Ntale HK, Halldin S (2009) Temporal rainfall variability in the Lake Victoria Basin in East Africa during the twentieth century. Theoretical and Applied Climatology 98:119-135

Knight JR, Folland CK, Scaife AA (2006) Climate impacts of the Atlantic Multidecadal Oscillation. Geophysical Research Letters 33:L17706

Kundzewicz ZW, Robson AJ (2004) Change detection in hydrological records - a review of the methodology. Hydrological Sciences Journal 49: 7-19

Lazaro R, Rodrigo FS, Gutierrez L, Domingo F, Puigdefabregas J (2001) Analysis of a 30-year rainfall record (1967-1997) in semi-arid SE Spain for implications on vegetation. Journal of Arid Environments 48:373-395. doi:10.1006/jare.2000.0755

Lopez A, Wilby RL, Fung F, New M (2011) Emerging approaches to climate risk management. In: Fung F, Lopez A, New M (eds) Modelling the Impact of Climate Change on Water Resources. Wiley-Blackwell, Chichester, pp 128-135

Lorenzo MN, Iglesias I, Taboada JJ, Gómez-Gesteira M (2010) Relationship between monthly rainfall in northwest Iberian Peninsula and North Atlantic sea surface temperature. International Journal of Climatology 30:980-990

Ma LH, Han YB, Yin ZQ (2010) Possible Influence of the 11-year Solar Cycle on Precipitation in Huashan Mountain of China over the Last 300 Years. Earth, Moon, and Planets 107:219224

Macdonald N, Philips ID, Thorpe J (2008) Reconstruction of long-term precipitation records of Edinburgh: an examination of the mechanisms responsibility of temporal variability in precipitation. Theoretical and Applied Climatology 92:141-154

Mansell MG (1997) The effects of climate change on rainfall trends and flooding risk in the West of Scotland. Nordic Hydrology 28:37-50

Mason PJ (2010) Climate variability in civil infrastructure planning. Proceedings of ICE 163:7480

Massei N, Laignel B, Deloffre J, Mesquita J, Motelay A, Lafite R, Durand A (2010) Long-term hydrological changes of the Seine River flow (France) and their relation to the North Atlantic Oscillation over the period 1950-2008. International Journal of Climatology 30:2146-2154

Mayes J (1996) Spatial and temporal fluctuations of monthly rainfall in the British Isles and variations in the mid-latitude westerly circulation. International Journal of Climatology 20:347-364

Mayes J (2000) Changing regional climatic gradients in the United Kingdom. Geographical Journal 166:125-138

Milly PCD, Betancourt J, Falkenmark M, Hirsch RM, Zbigniew W, Kundzewicz D, Lettenmaier DP, Stouffer RJ (2008) Stationarity is dead: whither water management? Science 319:573-574

Mitosek HT (1995) Climate variability and change within the discharge time series: a statistical approach. Climatic Change 29:101-116 
Modarres R, Sarhadi A (2009) Rainfall trend analysis of Iran in the last half of the twentieth century. Journal of Geophysical Research 114 (D03101). doi:10.1029/2008JD010707

Murdoch J, Barnes JA (1974) Statistical Tables for Science, Engineering, Management and Business Studies. Second edn. Macmillan, London

Nasri M, Modarres R (2009) Dry spell trend analysis of Isfahan Province, Iran. International Journal of Climatology 29:1430-1438

Osborn TJ, Hulme M, Jones PD, Basnett TA (2000) Observed trends in the daily intensity of United Kingdom precipitation. International Journal of Climatology 20:347-364

Partal T, Kahya E (2006) Trend analysis in Turkish precipitation data. Hydrological Processes 20:2011-2026

Phillips ID, McGregor GR (2002) The relationship between monthly and seasonal South-west England rainfall anomalies and concurrent North Atlantic sea surface temperatures. International Journal of Climatology 22:197-217

Schmidli J, Frei C (2005) Trends of heavy precipitation and wet and dry spells in Switzerland during the 20th century. International Journal of Climatology 25:753-771

Seleshi Y, Demaree GR, Delleur JW (1994) Sunspot numbers as a possible indicator of annual rainfall at Addis-Ababa, Ethiopia. International Journal of Climatology 14:911-923

Sen PK (1968) Estimation of the regression coefficient based on Kendall's tau. Journal of the American Statistical Association 63:1379-1389

Serra C, Burgueno A, Martinez MD, Lana X (2006) Trends in dry spells across Catalonia (NE Spain) during the second half of 20th century. Theoretical and Applied Climatology 85:165-183

Smadi MM, Zghoul A (2006) A sudden change in rainfall characteristics in Amman, Jordan during the mid 1950s. American Journal of Environmental Sciences 2:84-91

Smith K (1995) Precipitation over Scotland, 1757-1992: Some aspects of temporal variability. International Journal of Climatology 15:543-556

Sutton RT, Hodson DLR (2005) Atlantic Ocean forcing of the North American and European summer climate. Science 309:115-118

Sweeney JC, O'Hare GP (1992) Geographical variations in precipitation yields and circulation types in Britain and Ireland. Transactions of the Institute of British Geographers 17:448463

Tabony RC (1979) A spectral and filter analysis of long-period rainfall records in England and Wales. The Meteorological Magazine 108:97-118

Thomas RG (1993) Rome rainfall and sunspot numbers. J Atmos Terr Phys 55:155-164

Torrence C, Compo GP (1998) A practical guide to wavelet analysis. Bulletin of the American Meteorological Society 79:61-78

Tošić I (2004) Spatial and temporal variability of winter and summer precipitation over Serbia and Montenegro. Theoretical and Applied Climatology 77:47-56

MIDAS Land Surface Station data (1853-current) NCAS British Atmospheric Data Centre (2006)

Waple AM (1999) The sun-climate relationship in recent centuries: a review. Progress in Physical Geography 23:309-328

Węglarczyk S (2009) On the stationarity of extreme levels of some Polish lakes. I. Preliminary results from statistical test. Limnological Reviews 9:129-138

Werritty A, Foster M Climate variability and recent changes in rainfall and river flows in Scotland. In: Lemmelä R, Helenius N (eds) Proceedings of the $2^{\text {nd }}$ International Conference on Climate and Water Espoo, Finland, 17-20 August 1998. pp 1110-1119

Werrity A (2002) Living with uncertainty: climate change, river flows and water resource management in Scotland. Science of the Total Environment 294:29-40

Worsley KJ (1979) On the likelihood ratio test for a shift in location of normal populations. Journal of the American Statistical Association 74:365-367

Yang Y, Tian F (2009) Abrupt change of runoff and its major driving factors in Haihe River Catchment, China. Journal of Hydrology 374:373-383

Yue S, Pilon P, Phinney B, Cavadias G (2002) The influence of autocorrelation on the ability to detect trend in hydrological series. Hydrological Processes 16:1807-1829 


\section{Figure captions:}

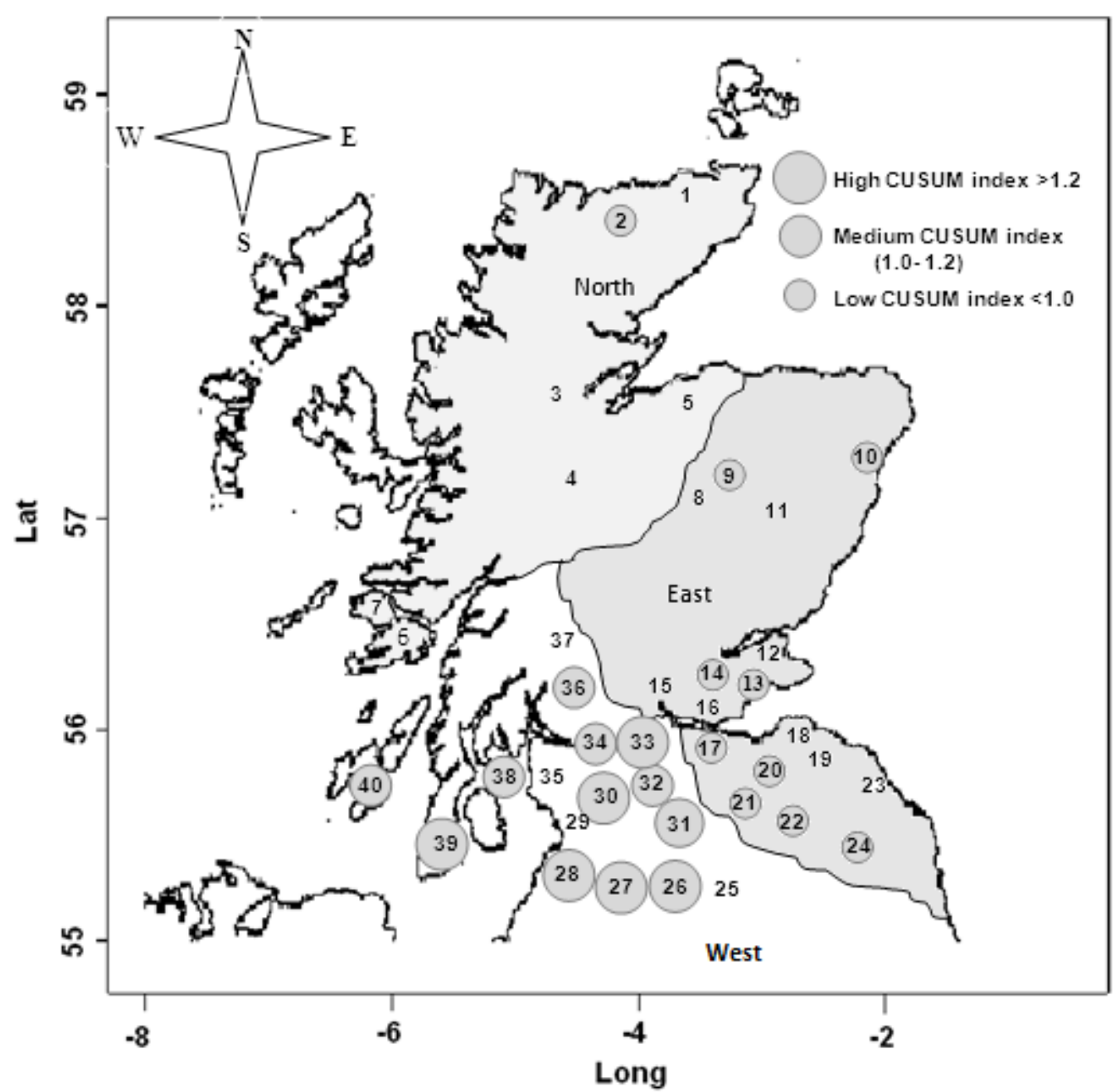

Fig. 1 Geographical location of the weather stations and rainfall variability in Scotland during the period 1961-2000 with the diameter of the circle depicting the magnitude of the annual CUSUM range at individual weather stations. Also shown are the three regions of Scotland: North, West, and East.

a) 


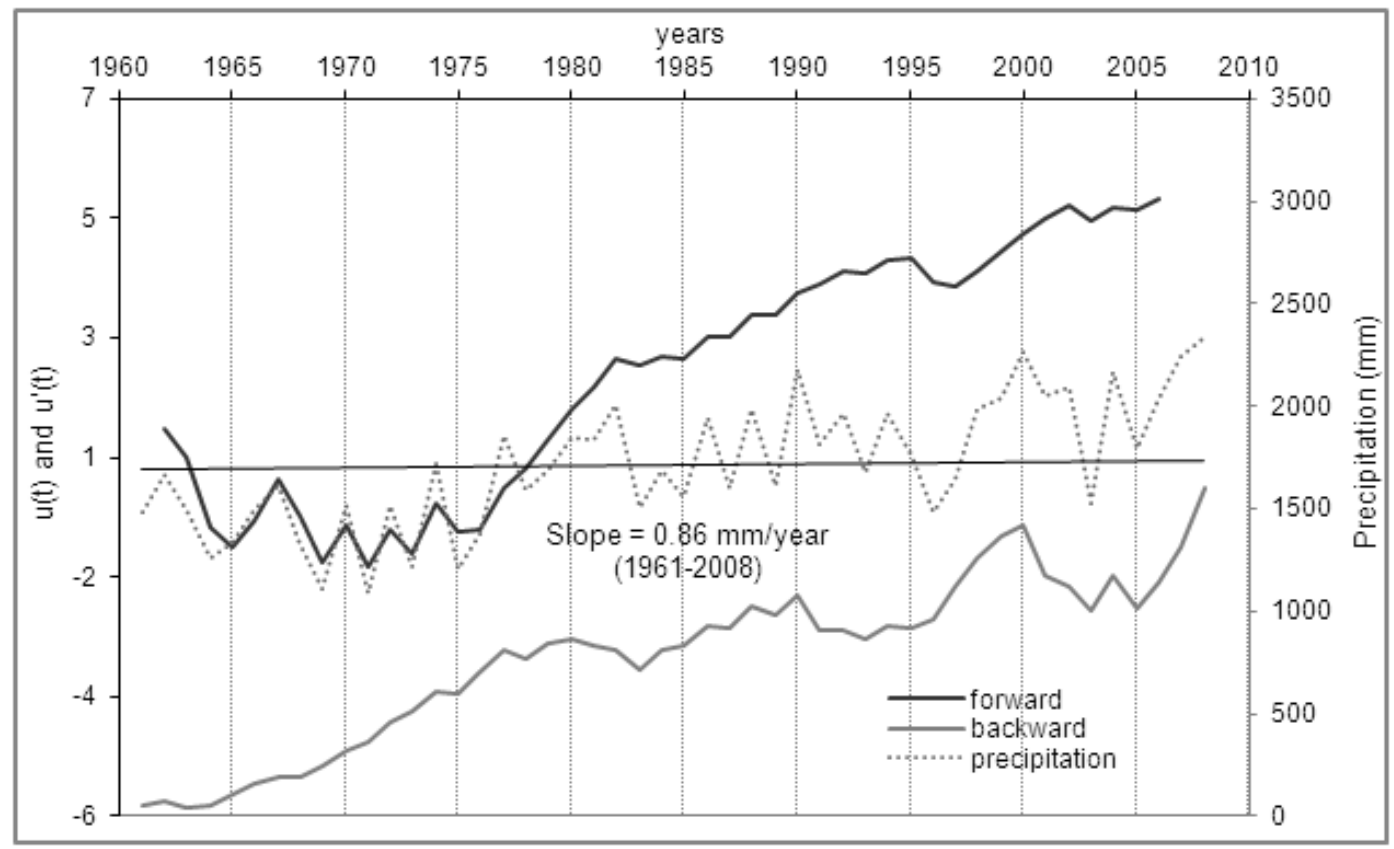

b)

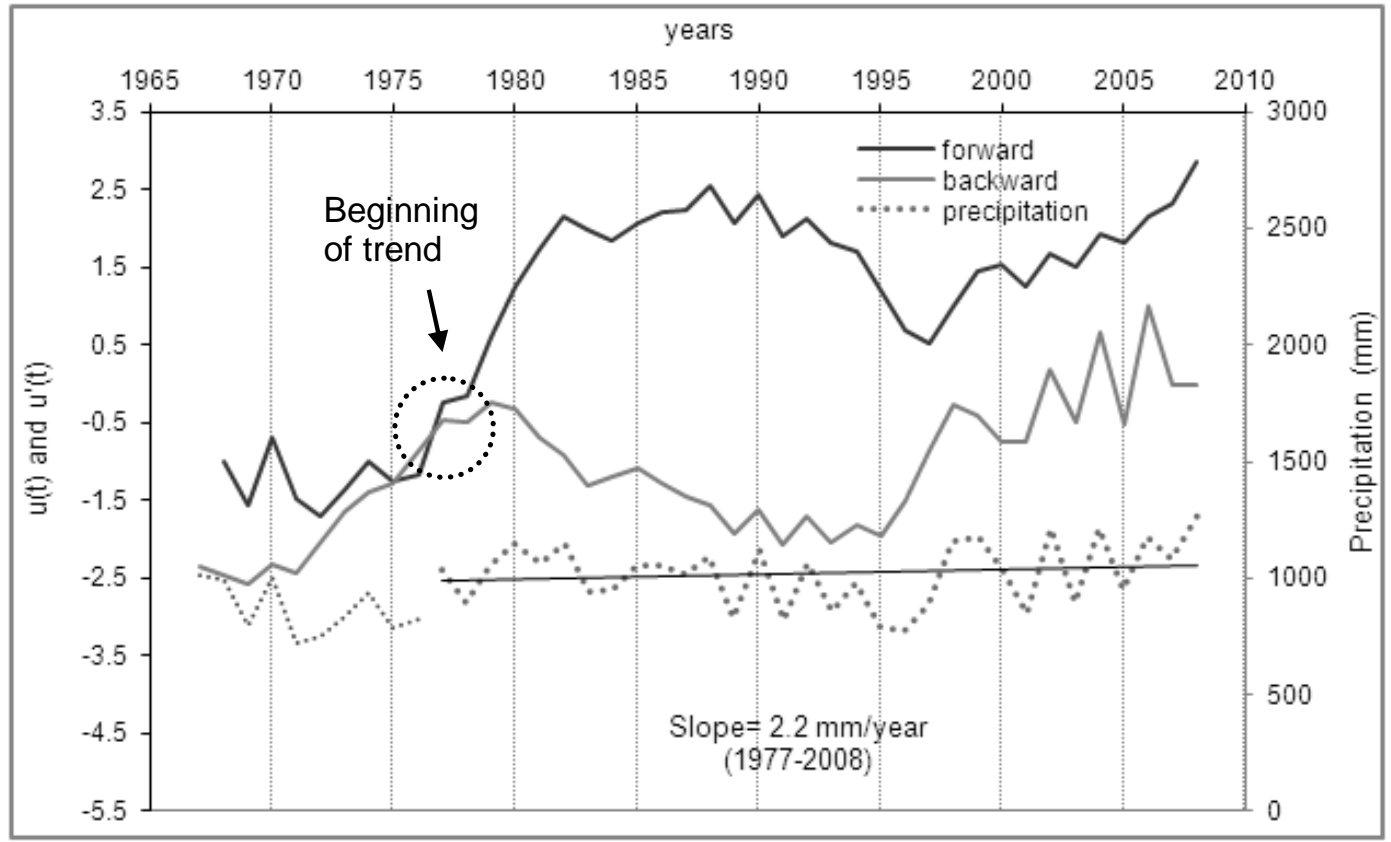


c)

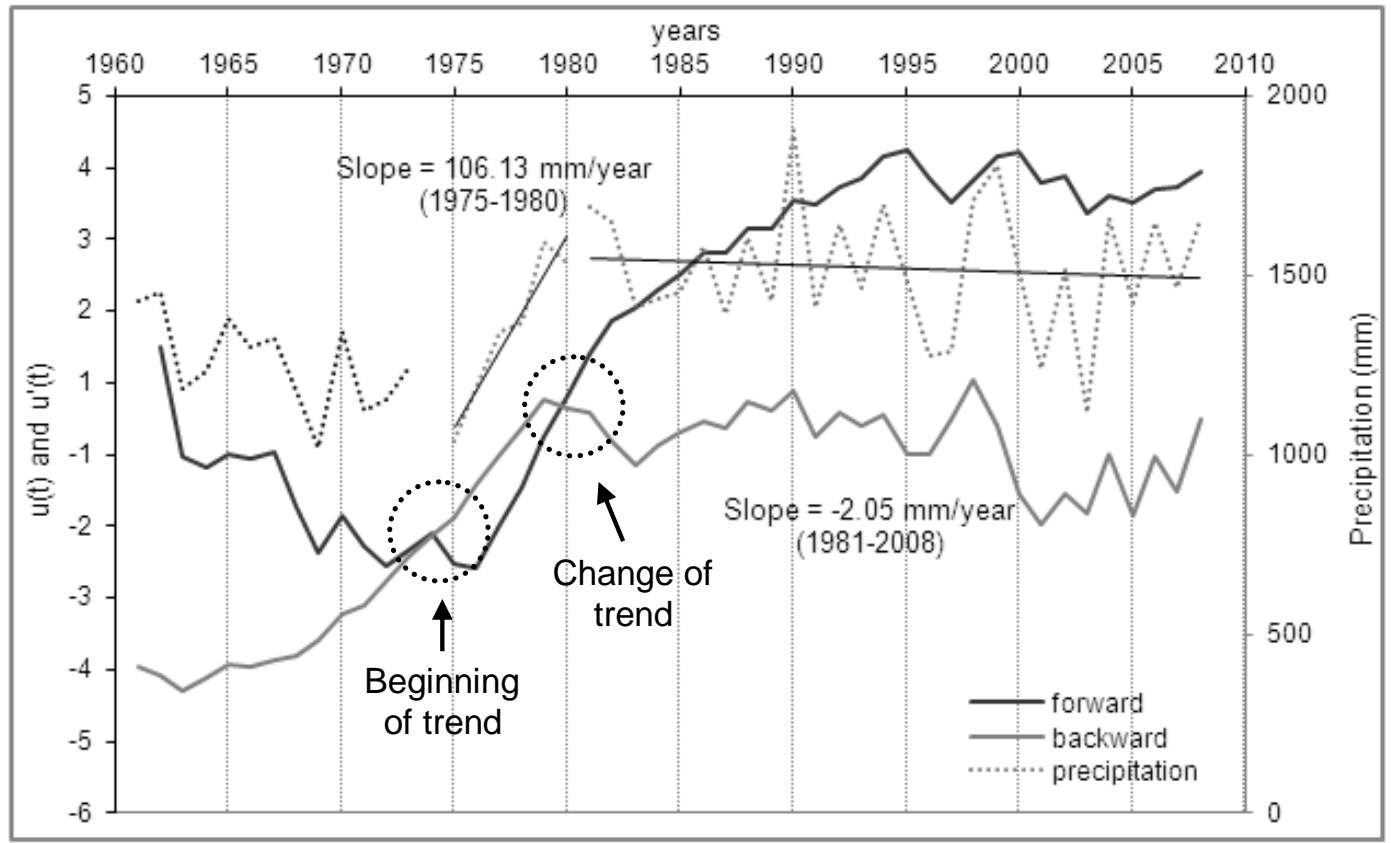

d)

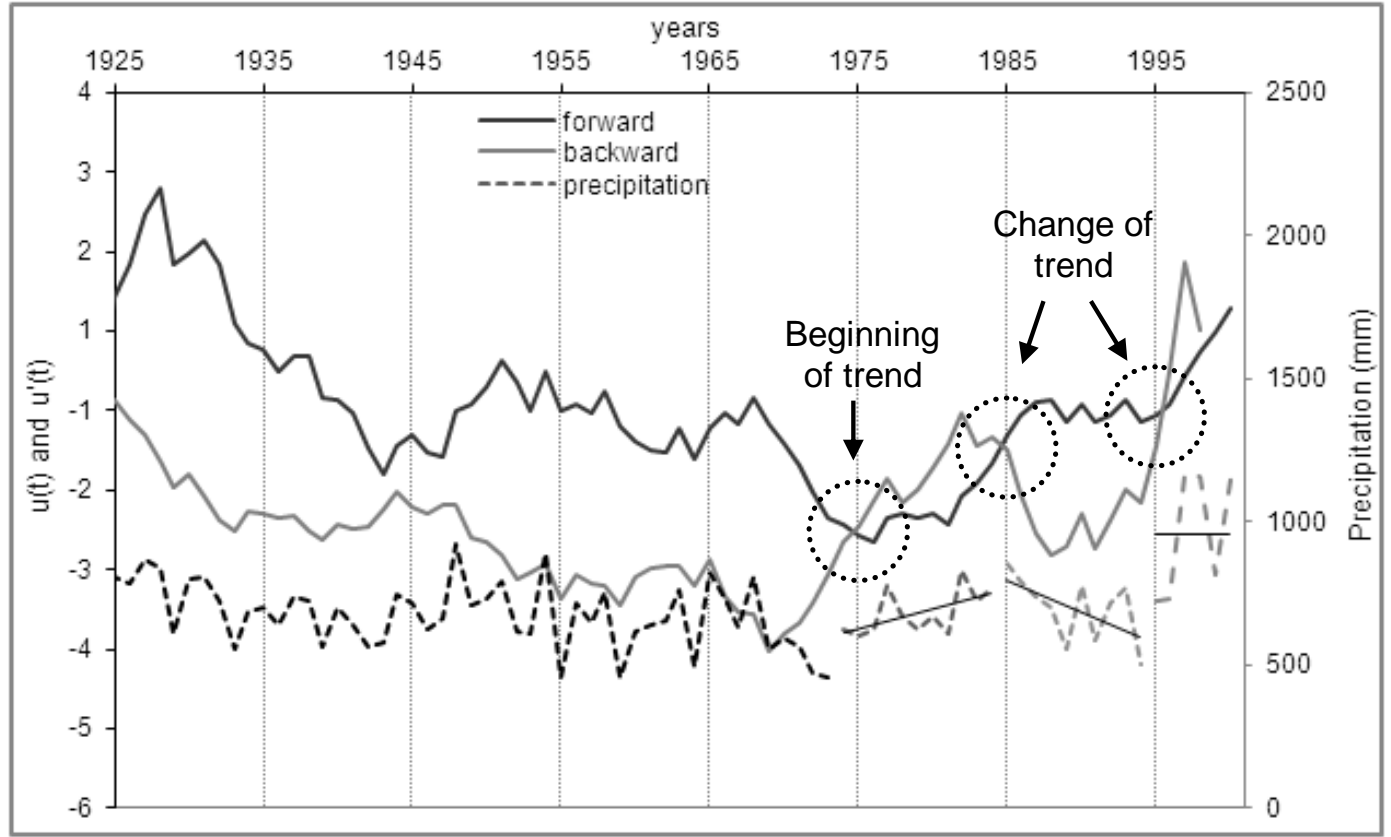

Fig. 2 Outcome of the sequential MK test applied to the total annual precipitation time series at Blackwood (a), Gailes (b), Skipness (c), and Edinburgh (d) 


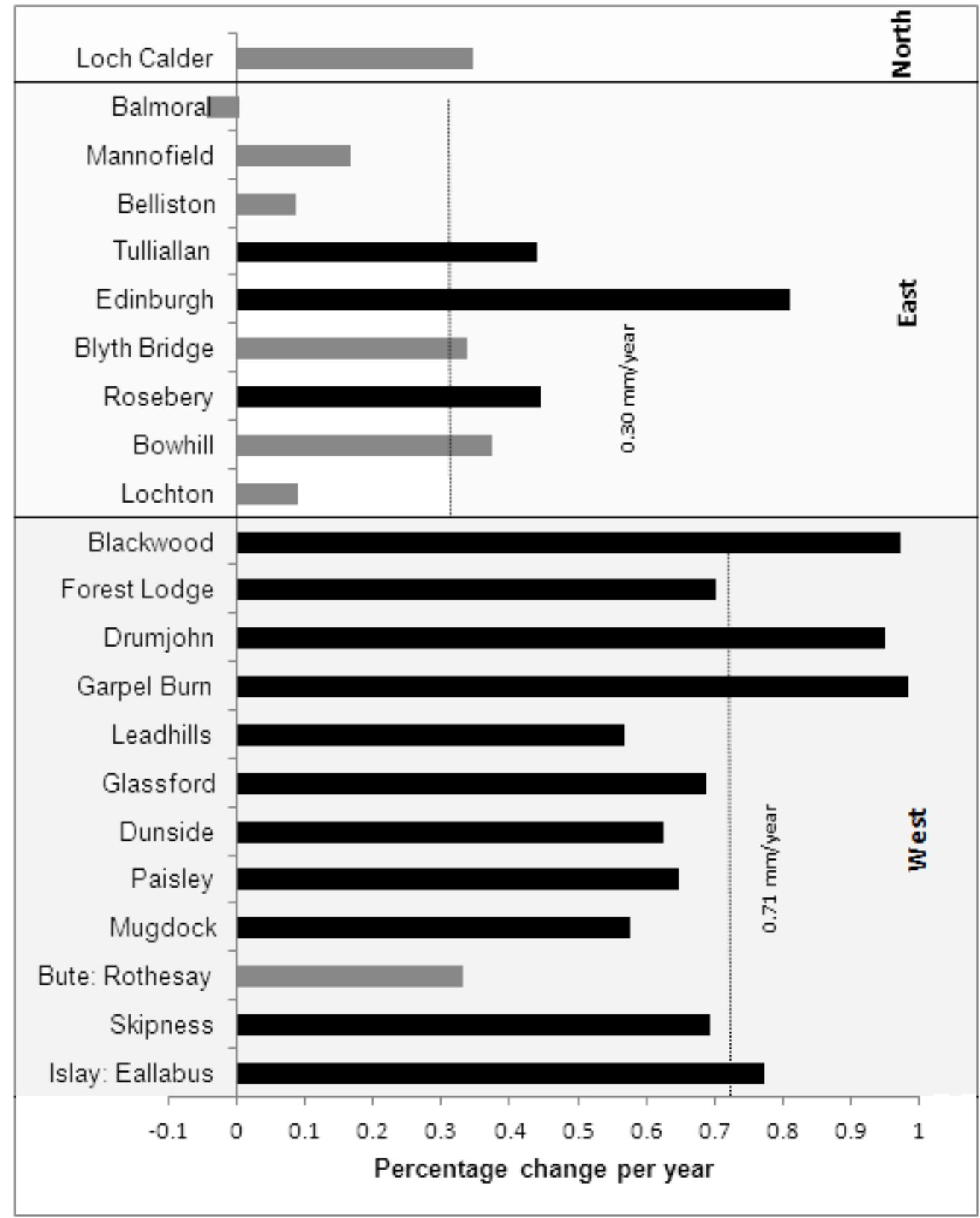

Fig. 3 Trends in total annual precipitation computed for the period 1961-2000 using the Theil-Sen approach. The black bars show the statistically significant trends at the $95 \%$ confidence level using the MK test. Also shown is the average percentage change in total annual precipitation per year for the East and West regions. 


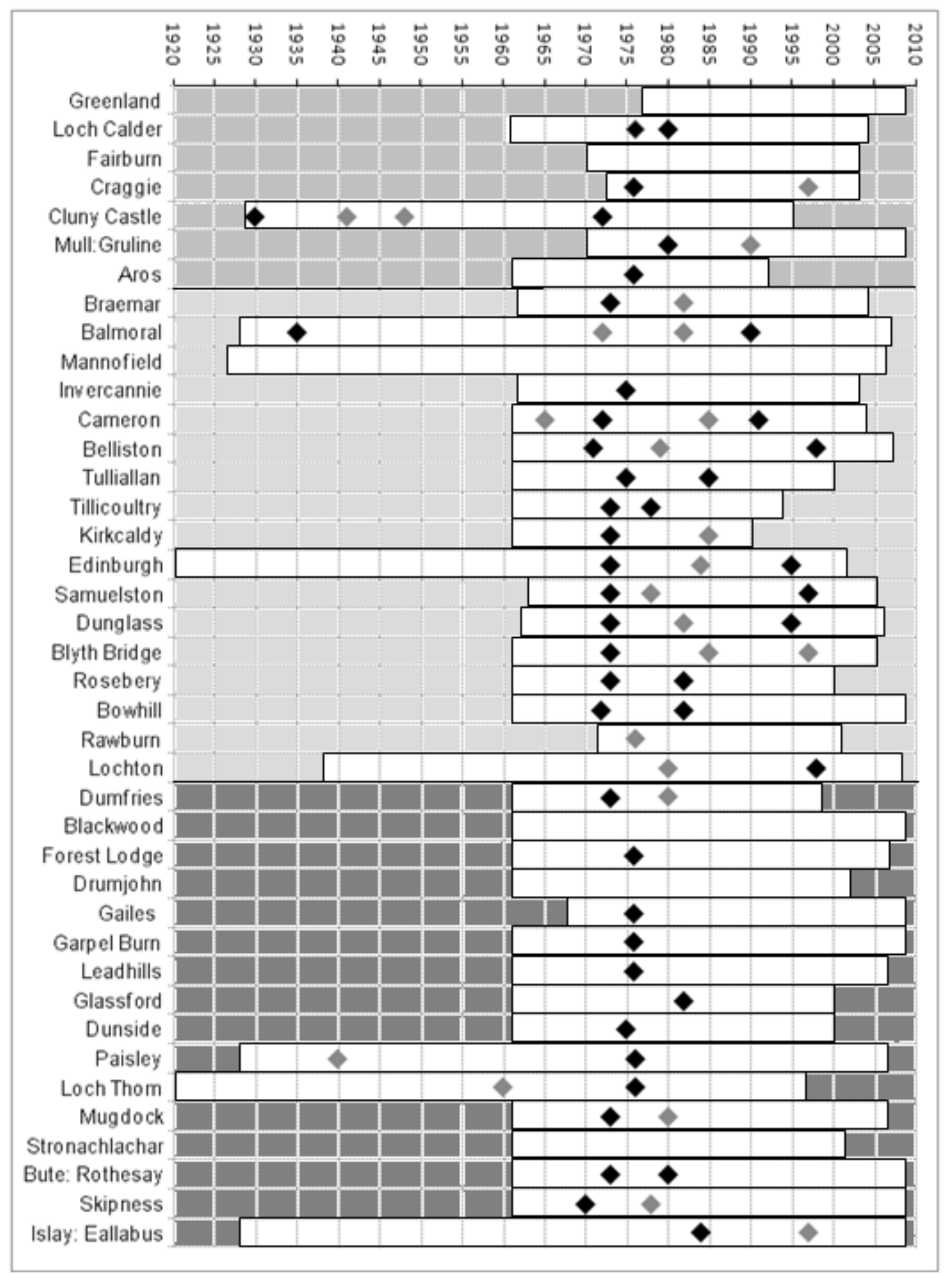

Fig. 4 Changes in trend in total annual precipitation identified by the sequential MK test, where the black and grey hexagons represent increasing and decreasing trends, respectively, following the identified change in trend for the three Scottish regions. 


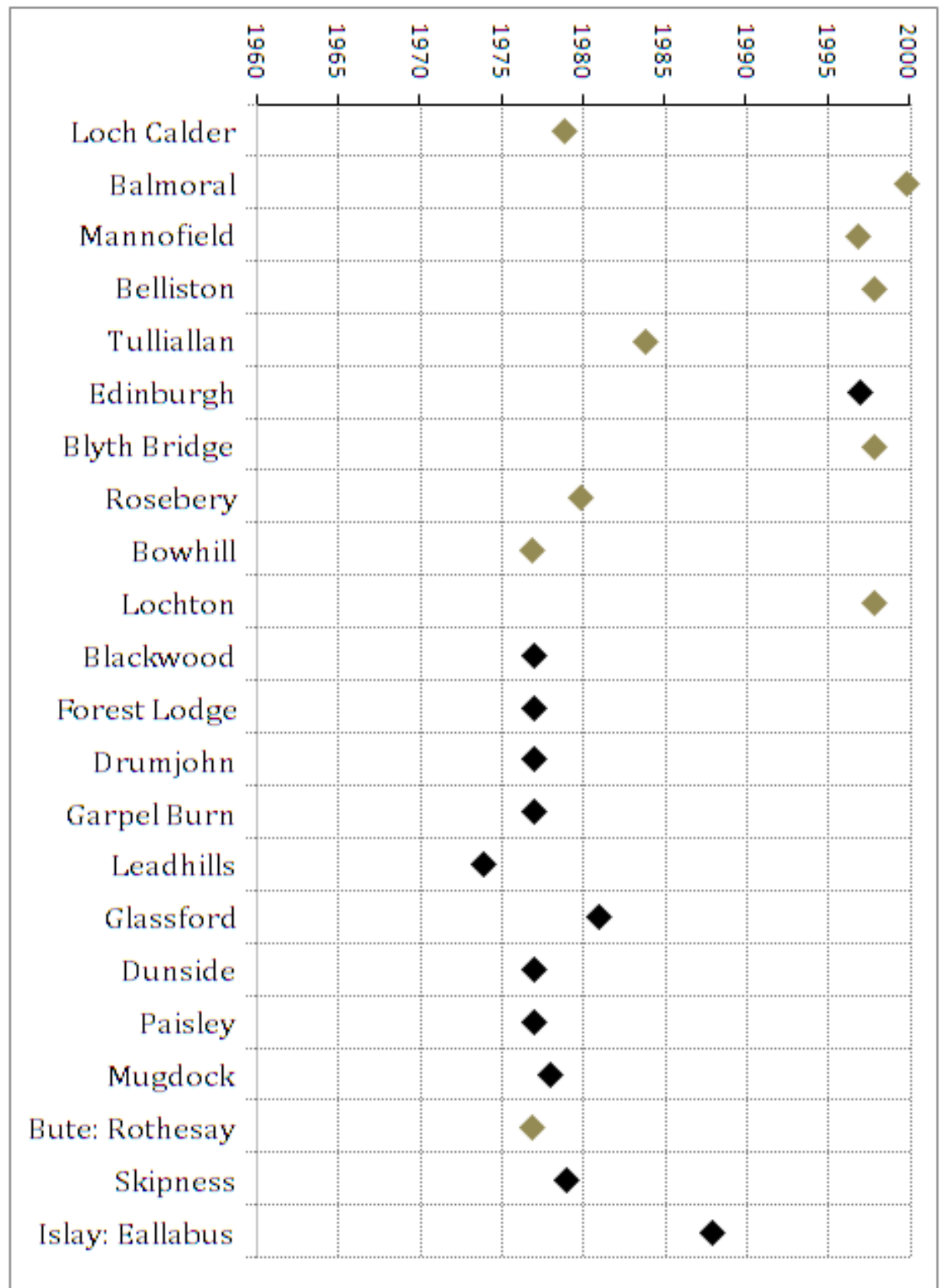

Fig. 5 Time occurrence of potential step change in the total annual precipitation time series using the WLR test. Black hexagons refer to statistically significant step changes at the $95 \%$ confidence level. 


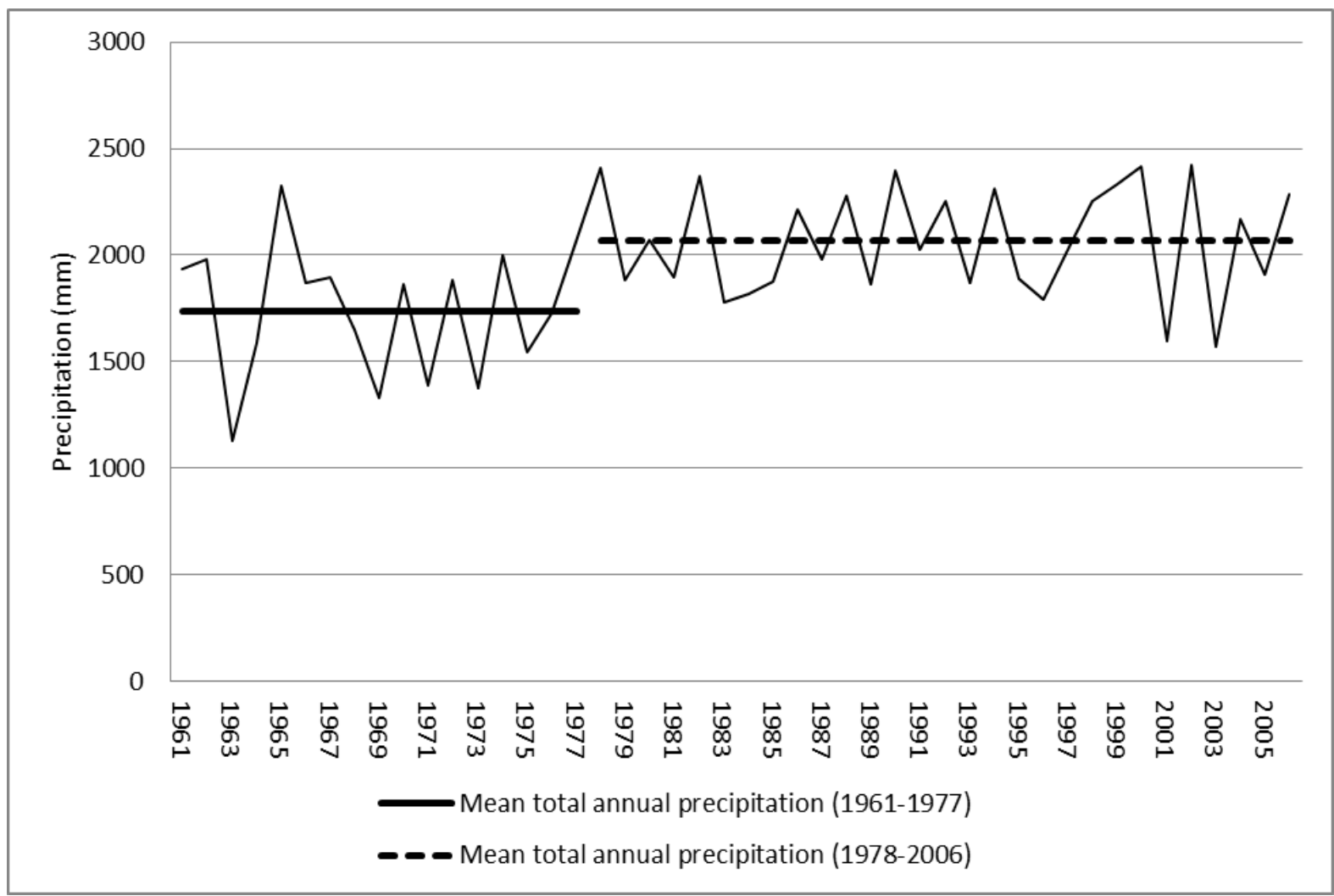

Fig. 6 Step change in the total annual precipitation time series of Blackwood as identified by the WLR test (a) and beginning of a trend in the total annual precipitation time series at Garpel Burn as identified by the sequential MK test (b). 


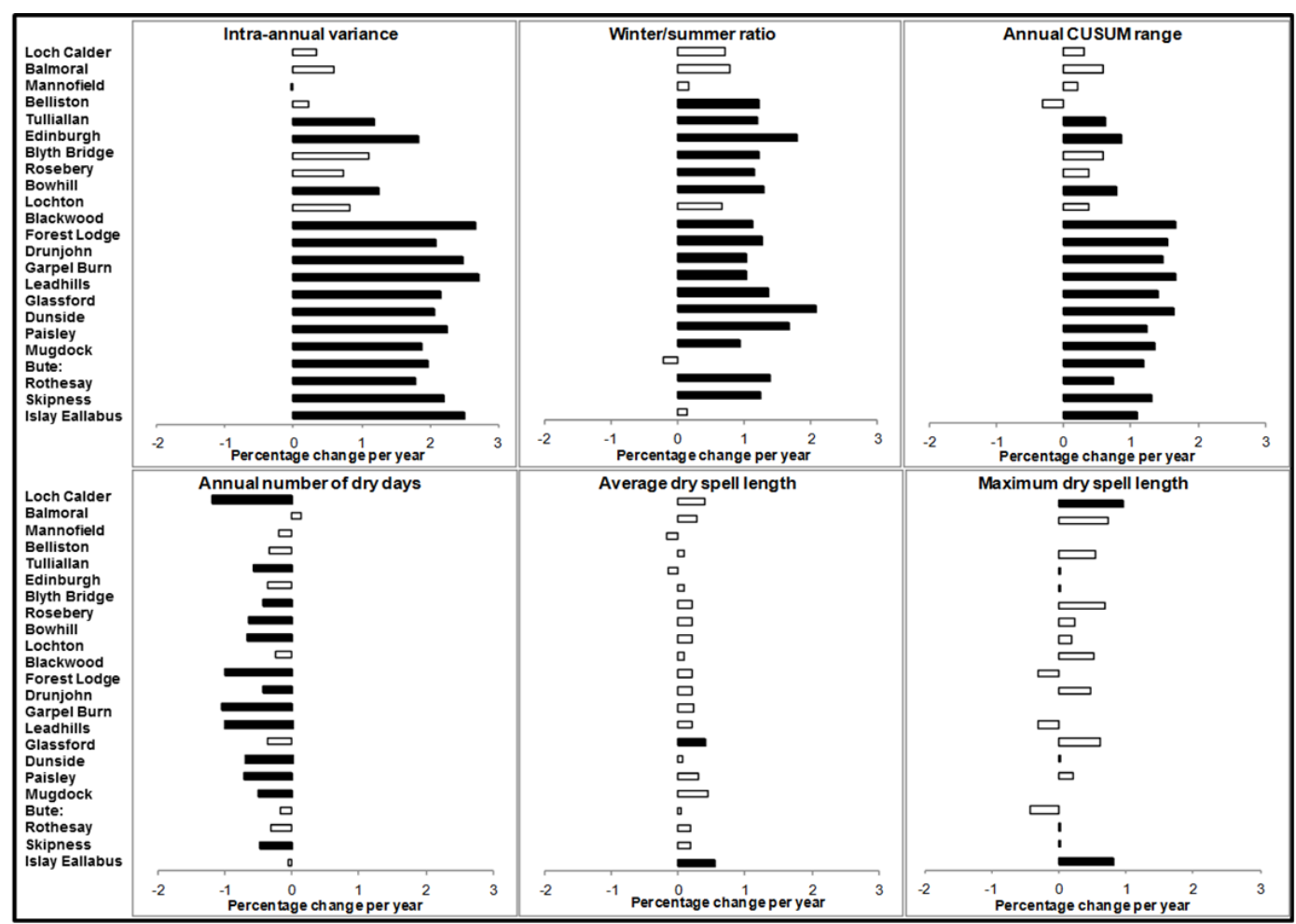

Fig. 7 Trends in rainfall variability (1961-2000) computed using the TSA. The black bars show the statistically significant trends at the $95 \%$ confidence level using the MK test. 


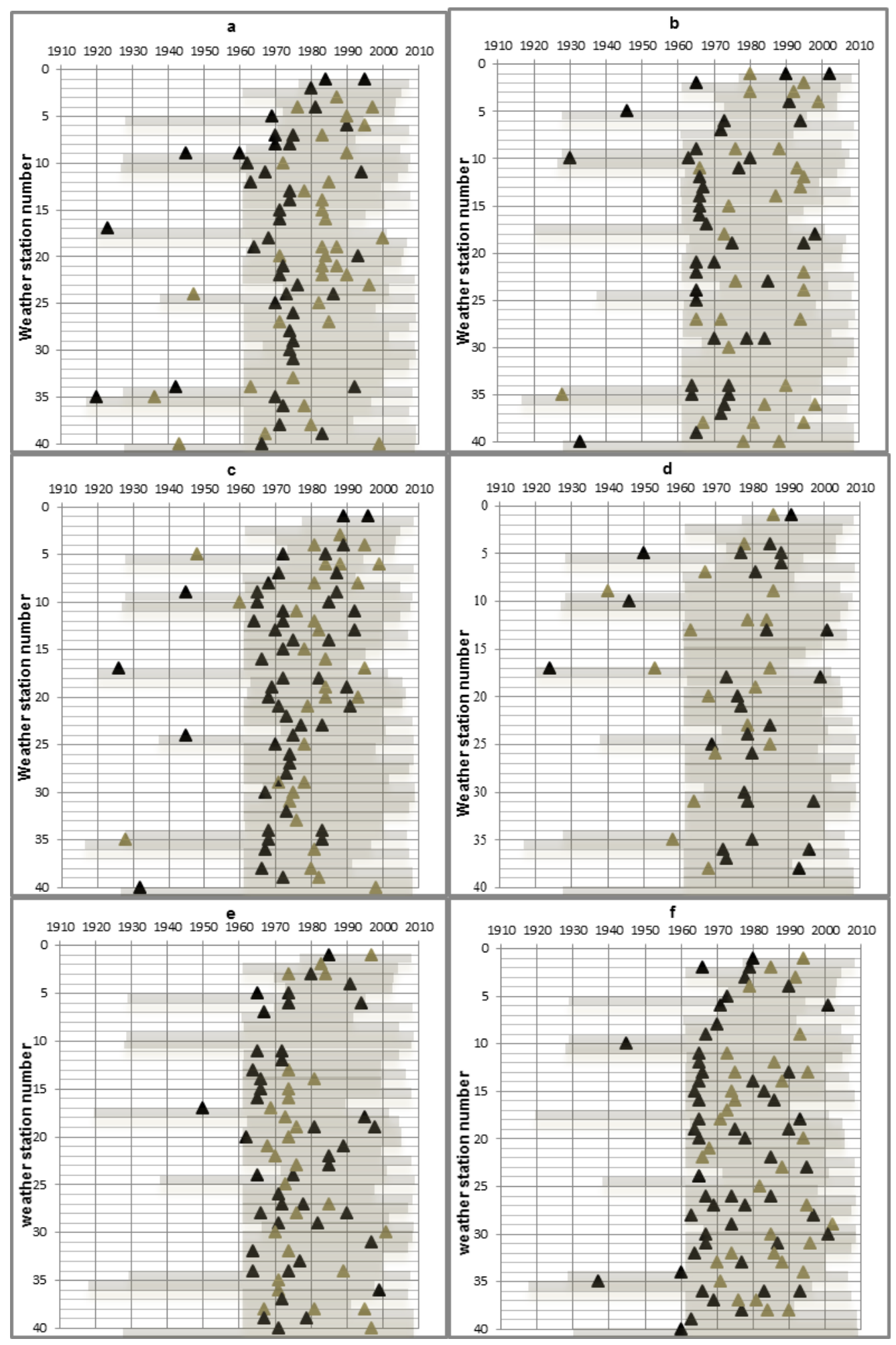

Fig. 8 Changes in trend identified using the sequential MK test for intra-annual variance (a), w/s precipitation ratio (b), annual CUSUM range (c), number of dry days (d), average dry spell length (e), and maximum dry spell length (f), where the black and grey triangles represent increasing and decreasing trends, respectively, following the identified change in trend. The grey bars correspond to the extent of the data records. 


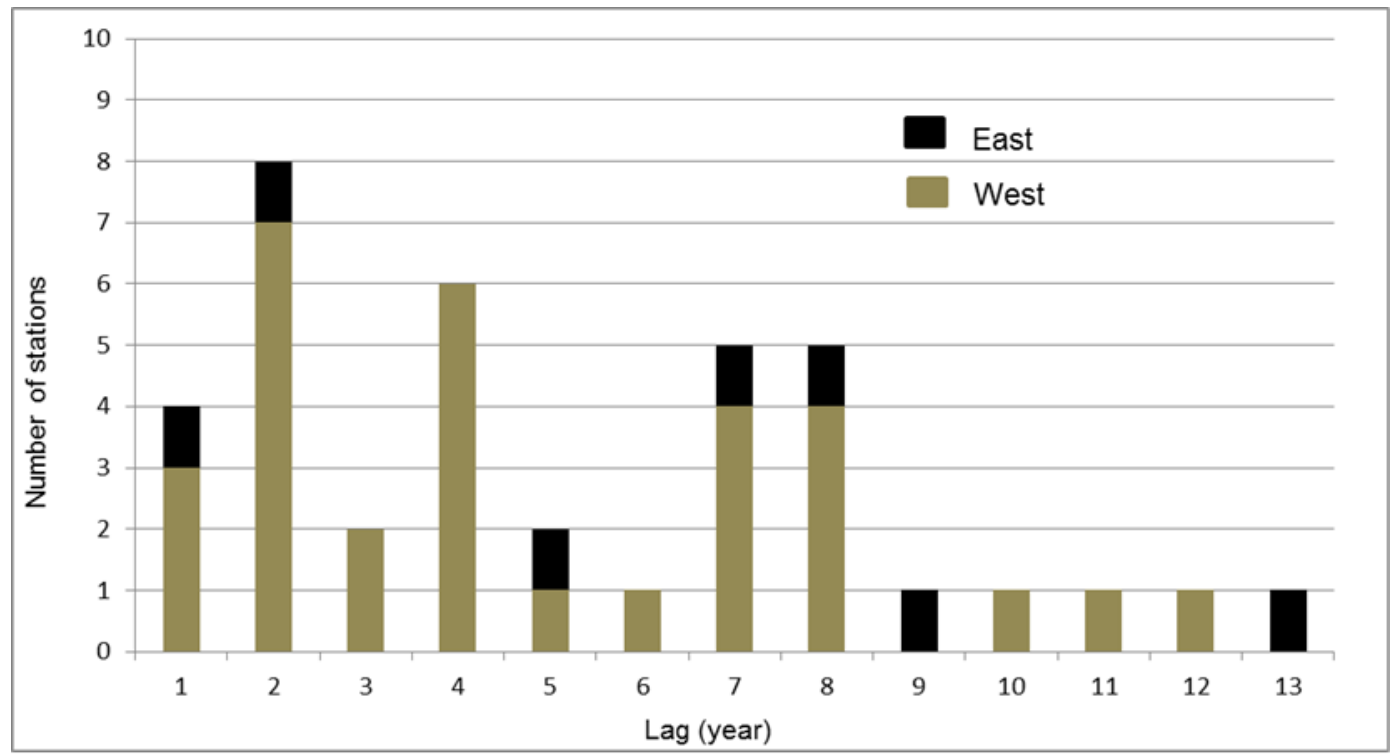

Fig. 9 Number of stations with statistically significant autocorrelation at the $95 \%$ confidence level at different lags 


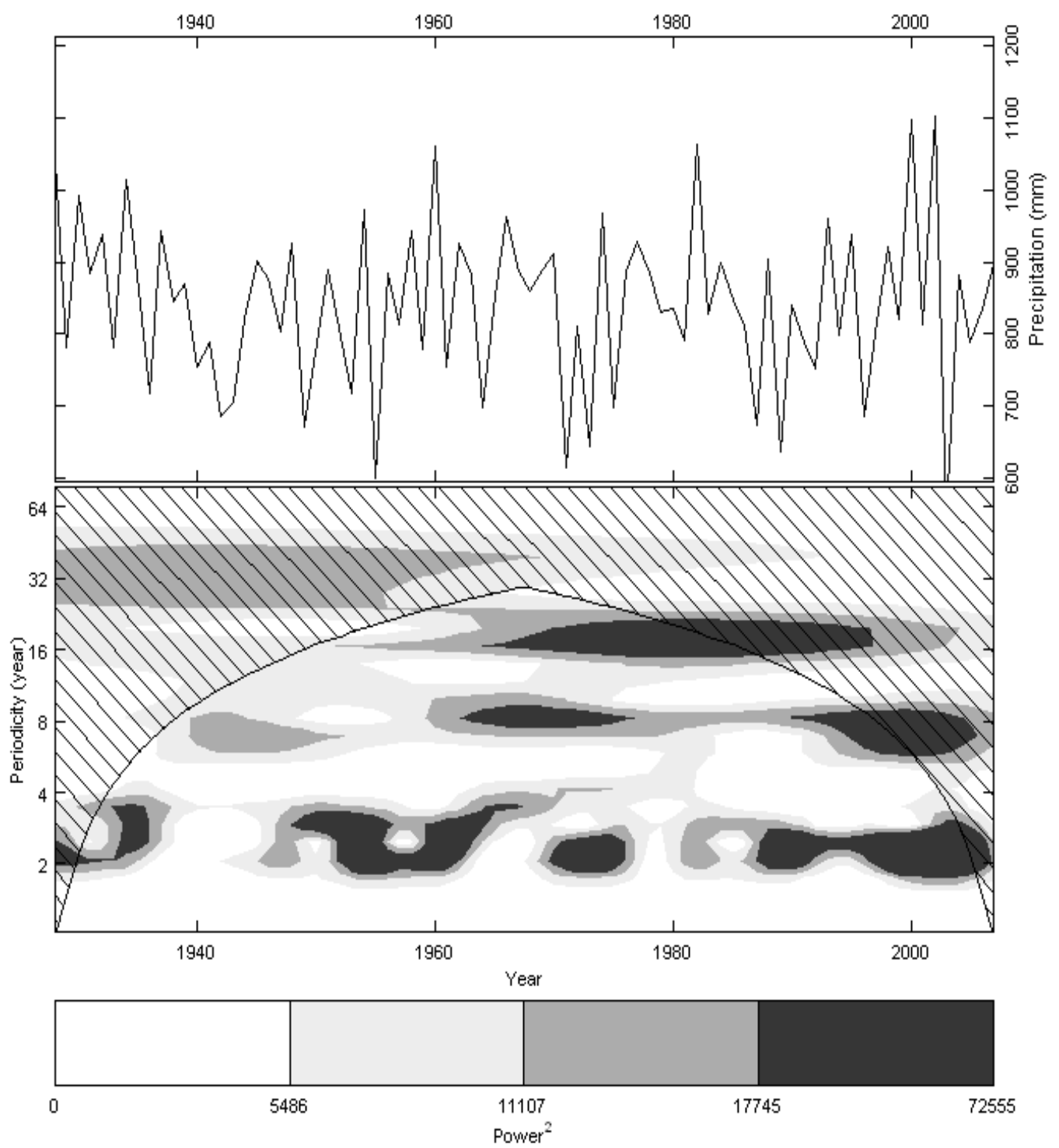

Fig. 10 Total annual precipitation at Balmoral (top) and wavelet analysis of that time series (bottom) for the period 1928-2007. 


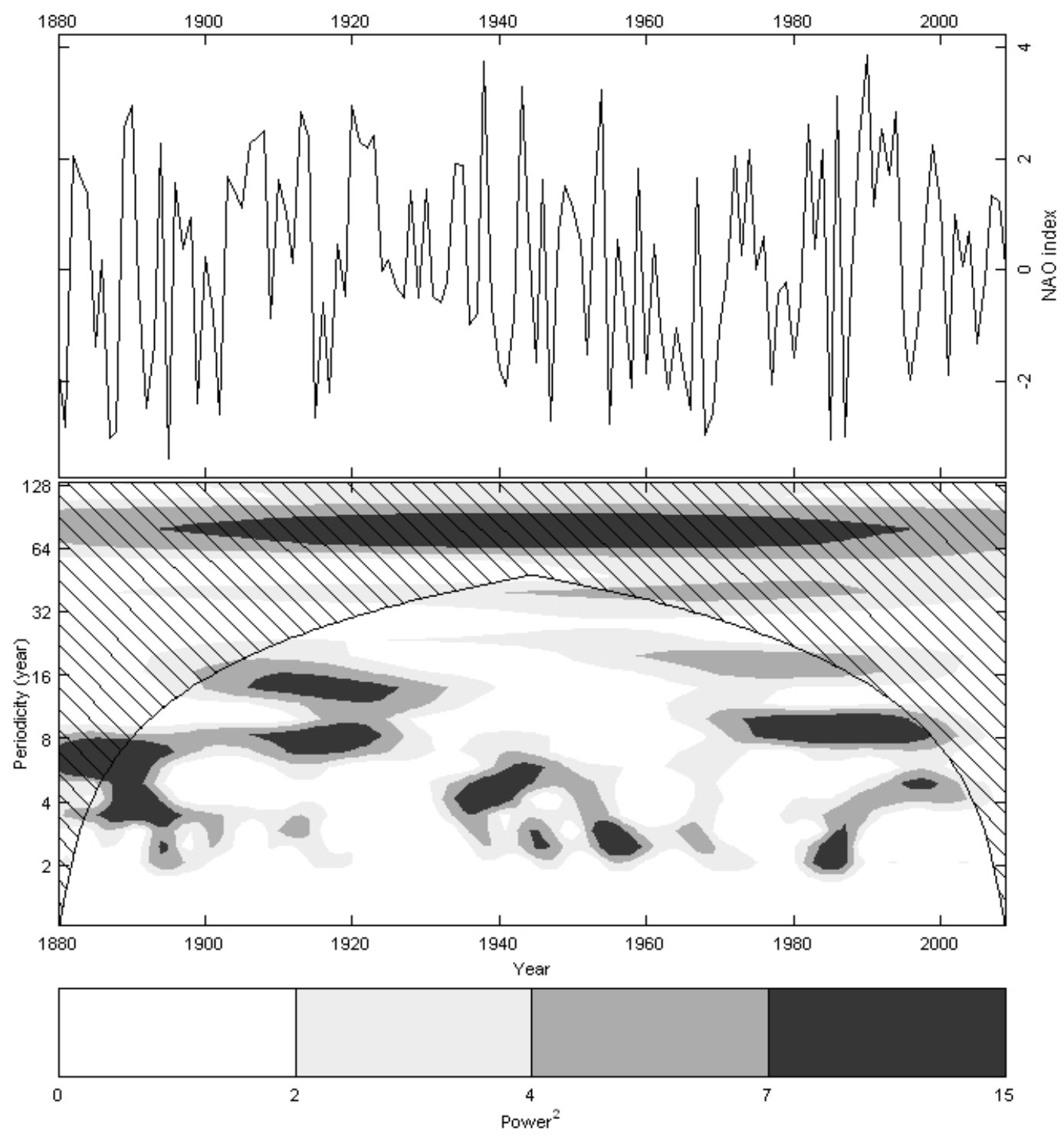

Fig. 11 Annual time series of the North Atlantic Oscillation (top) and wavelet analysis of that time series (bottom) for the period 1880-2009. 


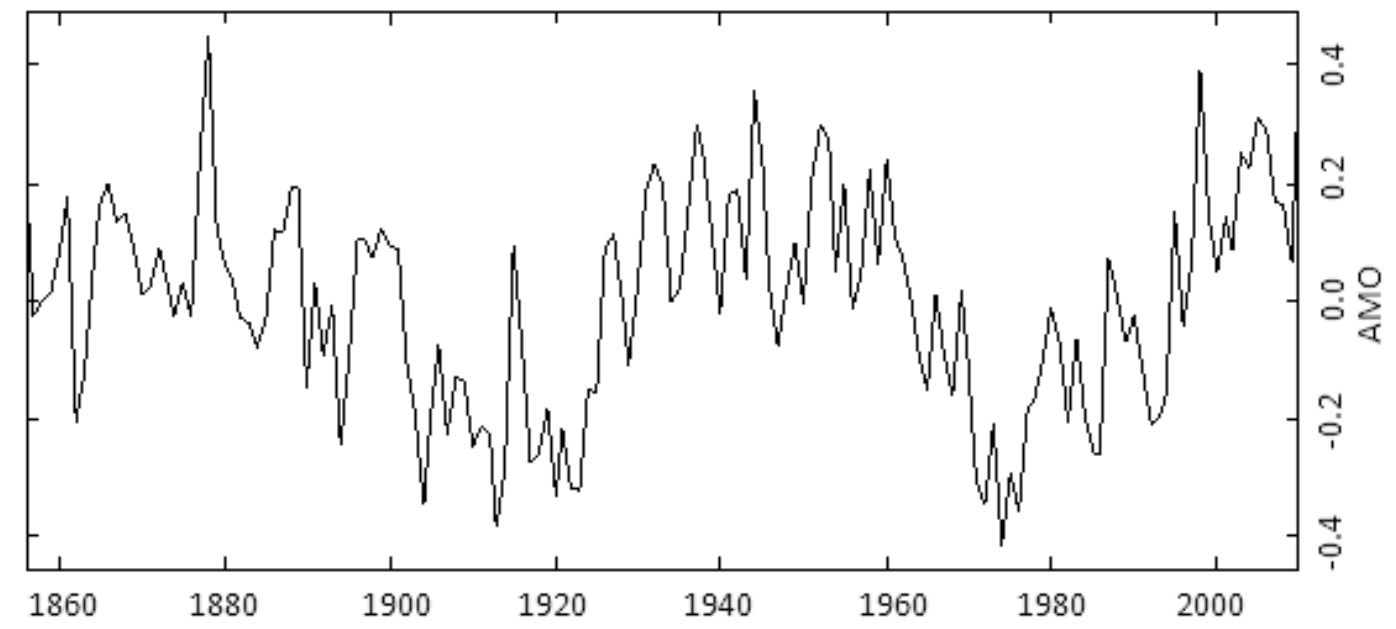

Fig. 12 Annual time series of the AMO for the period 1856-2010 
Table 1 Descriptive statistics of the selected weather stations (calculated using entire data record available). Shaded and clear rows correspond to weather stations situated in eastern and western Scotland, respectively, as depicted in Figure 1

\begin{tabular}{|c|c|c|c|c|c|c|c|c|c|c|c|}
\hline $\begin{array}{l}\text { Weather } \\
\text { station }\end{array}$ & $\begin{array}{l}\text { Ref. No } \\
\text { (Fig. 1) }\end{array}$ & Time-period & $\begin{array}{l}\text { WMO station } \\
\text { number }\end{array}$ & $\begin{array}{l}\text { Total annual } \\
\text { precipitation } \\
(\mathrm{mm})\end{array}$ & $\begin{array}{c}\text { Intra-annual } \\
\text { precipitation } \\
\text { variance } \\
\left(\mathrm{mm}^{2}\right)\end{array}$ & $\begin{array}{l}\text { Coefficient of } \\
\text { variation }\end{array}$ & $\begin{array}{c}\mathrm{w} / \mathrm{s} \\
\text { precipitation } \\
\text { ratio }\end{array}$ & $\begin{array}{c}\text { Annual } \\
\text { CUSUM range } \\
(\mathrm{mm})\end{array}$ & $\begin{array}{c}\text { Annual } \\
\text { number of dry } \\
\text { days }\end{array}$ & $\begin{array}{l}\text { Average dry } \\
\text { spell length } \\
\text { (day) }\end{array}$ & $\begin{array}{l}\text { Maximum dry } \\
\text { spell length } \\
\text { (day) }\end{array}$ \\
\hline & & \multicolumn{10}{|c|}{ North of Scotland } \\
\hline Greenland & 1 & $1977-2008$ & 14368 & 980.9 & 1557.7 & 0.11 & 1.6 & 173.6 & 91.5 & 4.0 & 16.8 \\
\hline Loch Calder & 2 & 1961-2004 & 14364 & 962.2 & 1564.4 & 0.13 & 1.7 & 174.0 & 119.3 & 3.8 & 14.8 \\
\hline Fairburn & 3 & $1970-2003$ & 14560 & 1028.9 & 2901.8 & 0.17 & 2.2 & 233.6 & 139.4 & 3.9 & 15.2 \\
\hline Craggie & 4 & 1973-2003 & 14705 & 690.7 & 968.3 & 0.15 & 1.0 & 121.7 & 151.1 & 4.0 & 16.0 \\
\hline Cluny Castle & 5 & $1928-1995$ & 14768 & 1009.9 & 2510.2 & 0.17 & 1.5 & 225.6 & 131.8 & 3.7 & 14.7 \\
\hline Mull: Gruline & 6 & $1970-2008$ & 14152 & 2081.8 & 9428.5 & 0.14 & 1.9 & 440.2 & 120.7 & 4.0 & 15.9 \\
\hline Aros & 7 & 1961-1992 & 900 & 1049.1 & 2291.4 & 0.13 & 1.7 & 210.6 & 164.6 & 4.2 & 17.7 \\
\hline & & \multicolumn{10}{|c|}{ East of Scotland } \\
\hline Braemar & 8 & $1962-2004$ & 147 & 900.9 & 1755.5 & 0.15 & 1.7 & 172.0 & 127.5 & 4.6 & 18.3 \\
\hline Balmoral & 9 & 1928-2007 & 148 & 841.1 & 1589.9 & 0.14 & 1.4 & 160.2 & 148.9 & 3.7 & 13.7 \\
\hline Mannofield & 10 & $1927-2006$ & 163 & 791.9 & 1374.3 & 0.16 & 1.2 & 144.8 & 165.5 & 3.7 & 13.8 \\
\hline Invercannie & 11 & $1962-2003$ & 14964 & 821.1 & 1766.6 & 0.17 & 1.4 & 160.9 & 156.2 & 3.8 & 15.8 \\
\hline Cameron & 12 & 1961-1999 & 15393 & 812.2 & 2095.9 & 0.21 & 1.2 & 152.7 & 165.3 & 4.0 & 15.9 \\
\hline Belliston & 13 & 1961-2007 & 237 & 739.4 & 1186.0 & 0.17 & 1.1 & 131.2 & 154.5 & 4.2 & 16.7 \\
\hline Tulliallan & 14 & 1961-2000 & 15450 & 837.2 & 1470.4 & 0.14 & 1.4 & 162.0 & 157.4 & 4.0 & 15.6 \\
\hline Tillicoultry & 15 & 1961-1994 & 15601 & 970.0 & 1699.4 & 0.13 & 1.3 & 176.4 & 152.5 & 4.0 & 15.9 \\
\hline Kirkcaldy & 16 & 1961-1990 & 15439 & 777.6 & 1169.4 & 0.17 & 1.2 & 137.8 & 159.2 & 4.1 & 15.7 \\
\hline Edinburgh & 17 & $1920-2002$ & 251 & 709.2 & 1492.9 & 0.22 & 0.9 & 140.9 & 156.2 & 4.1 & 16.2 \\
\hline Samuelston & 18 & 1963-2005 & 15844 & 618.6 & 931.4 & 0.17 & 0.9 & 118.7 & 164.3 & 4.1 & 15.9 \\
\hline Dunglass & 19 & $1962-2006$ & 15876 & 663.5 & 1032.5 & 0.18 & 1.0 & 124.3 & 176.4 & 4.0 & 14.9 \\
\hline Blyth Bridge & 20 & 1961-2005 & 274 & 905.3 & 1482.5 & 0.14 & 1.2 & 158.2 & 158.0 & 3.9 & 14.8 \\
\hline Rosebery & 21 & 1961-2000 & 15782 & 864.5 & 1414.4 & 0.15 & 1.3 & 153.0 & 147.7 & 3.8 & 14.5 \\
\hline Bowhill & 22 & $1961-2008$ & 279 & 876.9 & 1455.0 & 0.14 & 1.3 & 164.0 & 148.3 & 4.2 & 16.2 \\
\hline Rawburn & 23 & $1972-2001$ & 16057 & 877.9 & 1627.9 & 0.15 & 1.3 & 155.8 & 146.9 & 3.9 & 15.1 \\
\hline \multirow[t]{2}{*}{ Lochton } & 24 & $1938-2008$ & 16021 & 631.1 & 996.5 & 0.17 & 1.0 & 119.4 & 167.8 & 3.9 & 15.4 \\
\hline & & \multicolumn{10}{|c|}{ West of Scotland } \\
\hline Dumfries & 25 & 1961-1998 & 1017 & 1051.5 & 2373.7 & 0.13 & 1.6 & 212.3 & 163.3 & 4.2 & 17.5 \\
\hline Blackwood & 26 & $1961-2008$ & 13224 & 1713.1 & 7198.7 & 0.18 & 2.1 & 381.4 & 130.2 & 4.0 & 15.4 \\
\hline Forest Lodge & 27 & 1961-2006 & 13290 & 1865.9 & 8860.8 & 0.16 & 2.3 & 446.6 & 140.4 & 4.1 & 15.6 \\
\hline Drumjohn & 28 & $1961-2002$ & 13281 & 1704.9 & 7156.4 & 0.17 & 2.1 & 383.5 & 126.4 & 4.0 & 15.1 \\
\hline Gailes & 29 & $1967-2008$ & 13419 & 982.9 & 1788.7 & 0.15 & 1.3 & 182.5 & 148.3 & 4.1 & 16.3 \\
\hline Garpel Burn & 30 & $1961-2008$ & 13378 & 1675.8 & 6833.2 & 0.17 & 2.1 & 367.1 & 131.1 & 4.0 & 15.4 \\
\hline Leadhills & 31 & $1961-2006$ & 983 & 1684.2 & 5841.3 & 0.16 & 1.6 & 330.5 & 131.6 & 3.7 & 14.4 \\
\hline
\end{tabular}




\begin{tabular}{|c|c|c|c|c|c|c|c|c|c|c|c|}
\hline Glassford & 32 & $1961-2000$ & 13588 & 1217.8 & 3648.6 & 0.17 & 1.7 & 264.8 & 137.2 & 4.2 & 18.4 \\
\hline Dunside & 33 & $1961-2000$ & 13569 & 1411.1 & 4462.8 & 0.15 & 1.7 & 292.6 & 142.3 & 3.9 & 13.7 \\
\hline Paisley & 34 & $1928-2006$ & 968 & 1141.5 & 2875.1 & 0.15 & 1.8 & 236.4 & 147.6 & 3.9 & 14.7 \\
\hline Loch Thom & 35 & $1917-1996$ & 13502 & 1781.1 & 5870.4 & 0.14 & 1.6 & 343.9 & 129.0 & 3.7 & 14.1 \\
\hline Mugdock & 36 & $1961-2006$ & 13632 & 1307.3 & 3420.1 & 0.13 & 1.4 & 257.1 & 150.5 & 3.9 & 16.0 \\
\hline Stronachlachar & 37 & 1961-1991 & 15523 & 2193.9 & 12099.0 & 0.14 & 2.1 & 499.6 & 136.2 & 4.2 & 16.4 \\
\hline Bute: Rothesay & 38 & 1961-2008 & 939 & 1411.4 & 3514.5 & 0.13 & 1.5 & 274.7 & 145.4 & 3.9 & 15.1 \\
\hline Skipness & 39 & 1961-2008 & 13845 & 1422.4 & 4005.5 & 0.14 & 1.6 & 287.1 & 143.3 & 3.9 & 15.3 \\
\hline Islay: Eallabus & 40 & $1928-2008$ & 13878 & 1343.1 & 3280.1 & 0.14 & 1.5 & 260.2 & 123.8 & 4.0 & 14.6 \\
\hline North & & & & 1114.8 & 3031.7 & 0.14 & 1.7 & 225.6 & 131.2 & 3.9 & 15.8 \\
\hline East & & & & 802.3 & 1443.6 & 0.16 & 1.2 & 148.9 & 156.0 & 4.0 & 15.5 \\
\hline West & & & & 1494.2 & 5201.8 & 0.15 & 1.7 & 313.8 & 139.2 & 3.9 & 15.5 \\
\hline $\begin{array}{l}\text { Scotland } \\
\text { average }\end{array}$ & & & & 1137.1 & 3225.7 & 0.15 & 1.5 & 229.4 & 142.1 & 3.9 & 15.6 \\
\hline
\end{tabular}


Table 2 Correlation matrix between the different measures of variability ${ }^{\mathrm{a}}$

\begin{tabular}{|c|c|c|c|c|c|c|}
\hline & $\begin{array}{c}\text { Intra-annual } \\
\text { precipitation } \\
\text { variance }\end{array}$ & $\begin{array}{c}\mathrm{w} / \mathrm{s} \\
\text { precipitation } \\
\text { ratio }\end{array}$ & $\begin{array}{c}\text { Annual } \\
\text { CUSUM } \\
\text { range }\end{array}$ & $\begin{array}{c}\text { Annual } \\
\text { number of } \\
\text { dry days }\end{array}$ & $\begin{array}{l}\text { Average dry } \\
\text { spell length }\end{array}$ & $\begin{array}{c}\text { Maximum } \\
\text { dry spell } \\
\text { length }\end{array}$ \\
\hline $\begin{array}{l}\text { Intra-annual } \\
\text { precipitation } \\
\text { variance }\end{array}$ & 1 & 0.47 & 0.95 & -0.51 & -0.08 & -0.06 \\
\hline $\begin{array}{l}\text { w/s precipitation } \\
\text { ratio }\end{array}$ & & 1 & 0.66 & -0.45 & 0.44 & 0.08 \\
\hline $\begin{array}{l}\text { Annual CUSUM } \\
\text { range }\end{array}$ & & & 1 & -0.59 & 0.03 & -0.05 \\
\hline $\begin{array}{l}\text { Annual number of } \\
\text { dry days }\end{array}$ & & & & 1 & 0.16 & 0.09 \\
\hline $\begin{array}{l}\text { Average dry spell } \\
\text { length }\end{array}$ & & & & & 1 & 0.41 \\
\hline $\begin{array}{l}\text { Maximum dry spell } \\
\text { length }\end{array}$ & & & & & & 1 \\
\hline $\begin{array}{l}\text { Mean absolute } \\
\text { correlation } \\
\text { coefficient }\end{array}$ & 0.41 & 0.42 & 0.45 & 0.35 & 0.22 & 0.13 \\
\hline
\end{tabular}

${ }^{a}$ Values in bold are statistically significant at the $95 \%$ confidence level 
Table 4 Periodicities identified using wavelet technique

a) 16-24 year periodicities

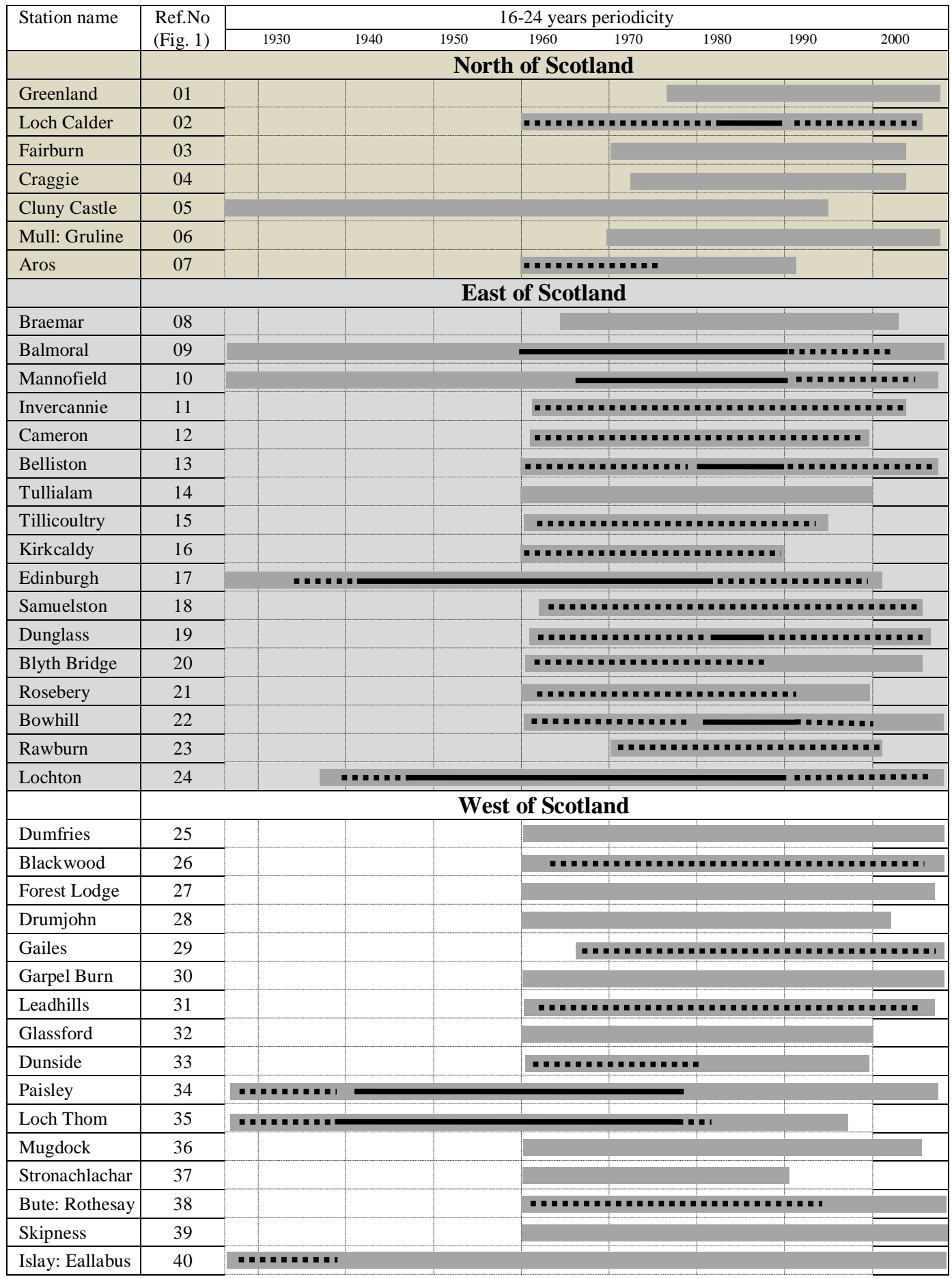

extent of precipitation record

extent of periodicity

extent of periodicity outside the cone of influence 
b) 7-10 year periodicities

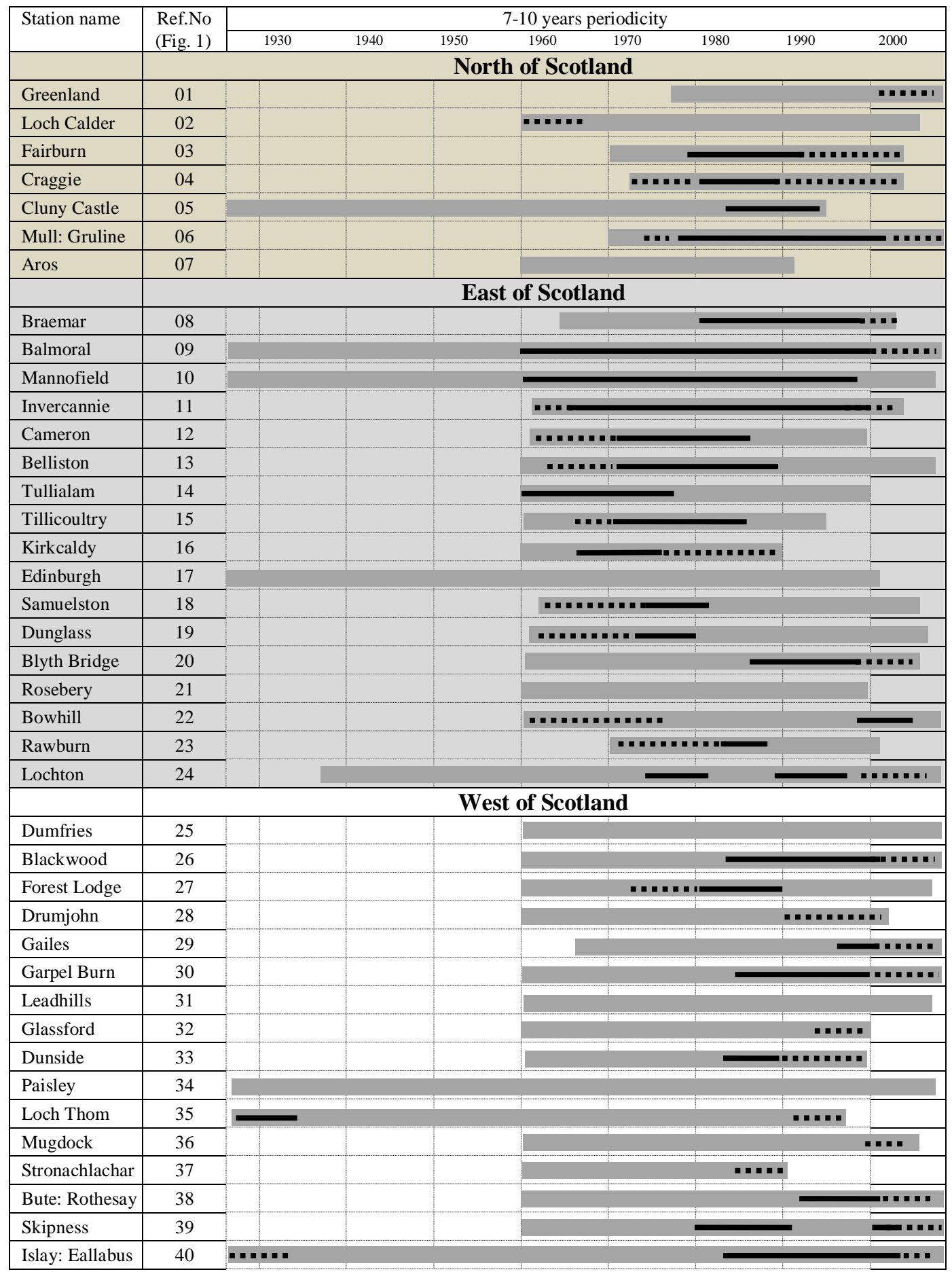


c) 4-7 year periodicities

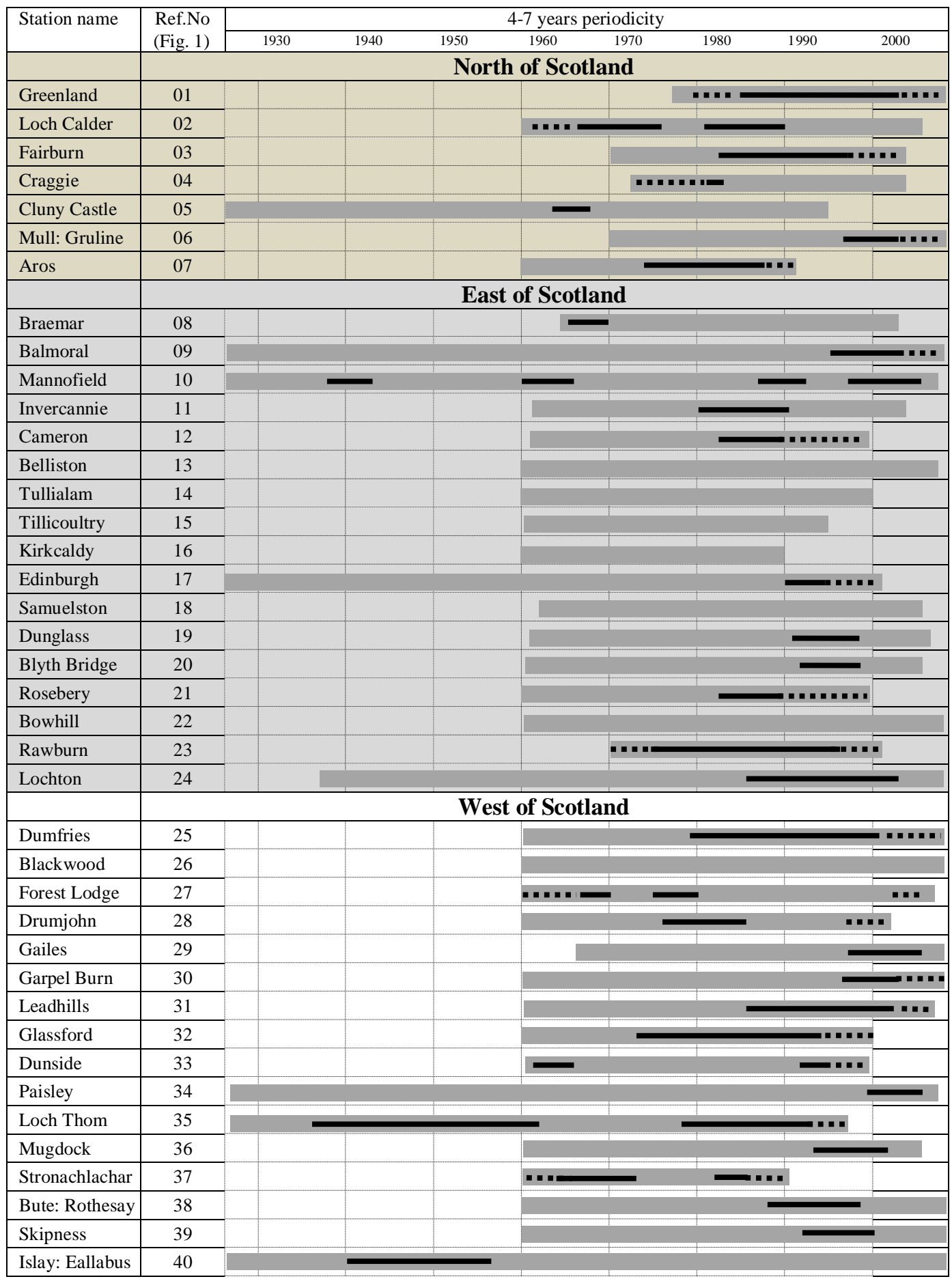


d) 2-4 year periodicities

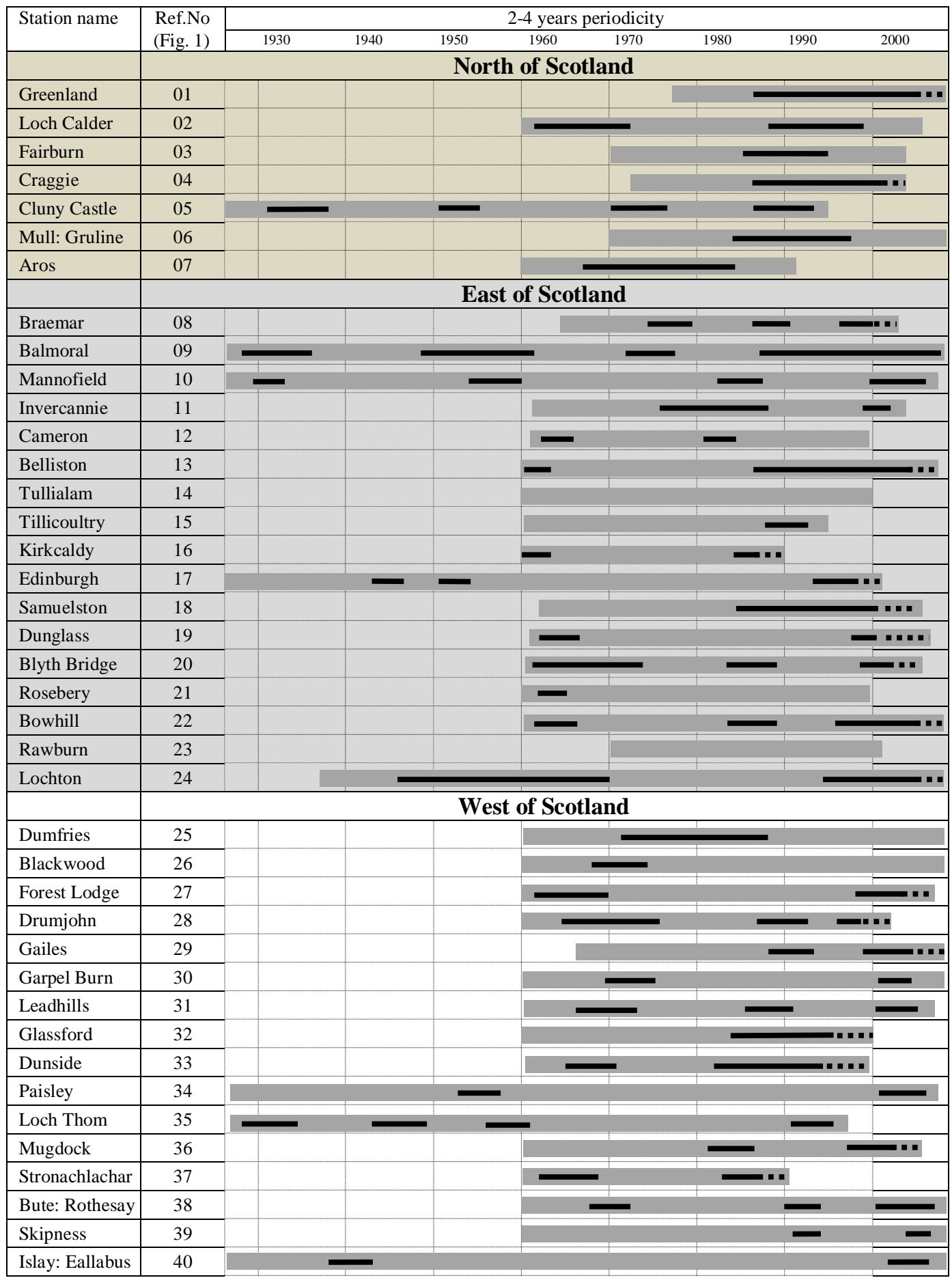

